\title{
THE PLEISTOCENE OF THE KATHARO BASIN (CRETE) AND ITS HIPPOPOTAMUS
}

\author{
by \\ G. J. BOEKSCHOTEN ${ }^{1)}$ AND P. Y. SONDAAR ${ }^{2}$ )
}

\section{CONTENTS}

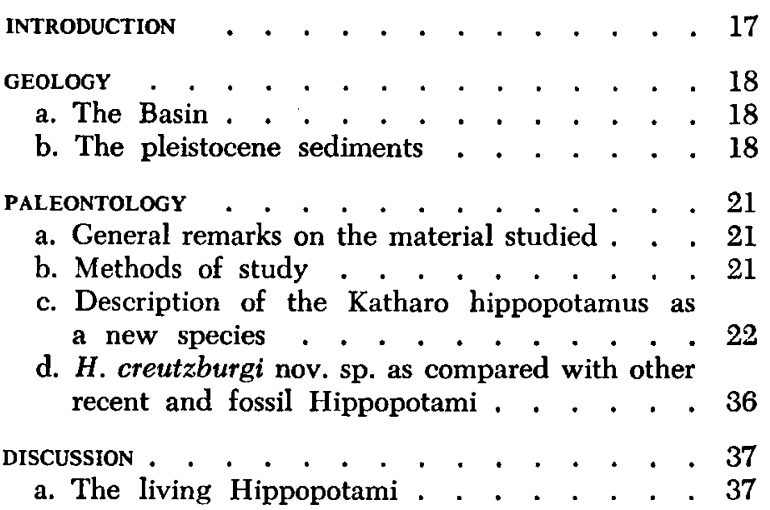

\section{INTRODUCTION}

Several Mediterranean islands have been inhabited by hippopotami of small stature during the Pleistocene. Those occurring on Sicily, Malta and Cyprus have received some attention; the Cretan Hippopotamus, however, thus far have hardly been studied.

The first to discover these fossils on Crete was the French geologist V. Raulin. He bought some jaw fragments from people of the Kritza village. The latter had brought these from their pastures in the Katharo basin, which is situated at a height of 1100 $m$ amidst the Dhikti mountains. Although Raulin visited the Katharo, he did not find anything himself. The fossils were described by BlarnvinLe (1847).

Another early find was bought by Graves in Megalokastro (now Iraklion). It consisted of some teeth, of unknown origin. These were described by Owen (1845). Somewhat later, other Hippopotamus material from Crete was recorded by LYDEKKER

1 Geologisch Instituut, Rijksuniversiteit Groningen, Melkweg 1, Groningen.

2 Geologisch Instituut, Rijksuniversiteit Utrecht, Oude Gracht 320, Utrecht. b. Morphological differences between $H$. amphibius and $H$. creutzburgi, and their significance

c. Manner of live of Hippopotamus creutzburgi on Pleistocene Crete . . . . . . . . 38

d. Origin and preservation of the Hippopotamus creutzburgi type . . . . . . . . . . . 38

e. Remarks on the problem of nanism . . . . 39

RÉSUMÉ . . . . . . . . . . . . . . . . 41

ZUSAMMENFASSUNG . . . . . . . . . . . 41

SUMMARY . . . . . . . . . . . . . . . 41

REFERENCES . . . . . . . . . . . . . . 41

(1885). Miss Bate was the first paleontologist to find Hippopotamus in Cretan pleistocene sediments herself. She organized excavations in the Katharo basin and in caves on the Northern coast of Crete; preliminary results were published in 1905. This fairly extensive material remained unstudied to the present.

The first author visited the Katharo in 1962, and, together with the second author, again in 1963. They revised the British Museum material in spring 1964. Almost simultaneously, Dr. Kuss commenced his researches on Pleistocene fossil vertebrates from the Island of Crete. It turned out that Dr. Kuss, not knowing of our Hippopotamus study under way, also started research on this subject. Another author who recently dealt with Greek Hippopotami is Dr. MELENTIS (1965) who published some data on Cretan hippo fossils in the Vienna Museum.

In the present study some data on the fossils, the stratigraphy and the origin of the Katharo basin fill will be furnished. The authors are indebted to Miss F. Feekes and Mr. R. R. van der Ploeg for their help in the field; to Dr. Sutcliffe for permission to study the British Museum collection; to Dr. Ginsburg 
for the material in the Paris Muséum d'Histoire Naturelle; to Dr. Kipp for that in the Utrecht Zoological Museum; to Prof. von Koenigswald for discussions on the subject; to Drs. van Bree for reading the manuscript critically; and to the Netherlands Organization for the Advancement of Pure Research for support in meeting the travel expenses of the second author in Crete.

\section{GEOLOGY}

\section{a. The basin}

The map (Fig. 1) shows the topographical situation. The Katharo is a basin-shaped, level depression of $4 \mathrm{~km}$ length and $1 \mathrm{~km}$ width in the Dhikti mountains (Fig. 2), which forms the eastern half of Middle Crete. Only part of the bottom of the valley is still covered by Pleistocene sediments. These are indicated on the map as dotted areas. Small erosion remnants were not included in the map. One of these is situated at the northeastern end of the valley, near Platani pigi.

The mountains at the northeastern side of the Katharo consist of well-bedded coarse conglomerates with a white limestone matrix. Sometimes fossils are found in this formation, among which Cerithium dertonense Sacco and Terebralia bidentata (Defrance) can be mentioned. The presence of the latter points to a Miocene age for these deposits. These mountains are the highest elevated Neogene strata of Crete.

The remaining mountains which encircle the Katharo largely consist of old limestones, which have not yielded fossils so far.

At several places (in the southeastern part of the basin near Avdheliakos and Pachykarmos) a flysch formation crops out. This consists of (usually much weathered) shales, slates and sandstones. Intercalated ultrabasic igneous rocks occur locally, e.g. near Platani pigi and Pachykarmos. At the first locality these were metamorphosed into steatite, which is exploited in a small quarry.

The soil of the Katharo is tilled by the villagers of Kritza. The main produce is corn; there are vineyards also. Vegetables are cultivated along the brooks. During the winter season the valley is covered by snow and uninhabited. The melt water flows off through some brooks which are mostly dry in summer. Therefore, the peasants were obliged to dig wells which generally reach the flysch surface underneath the Pleistocene. The brooks conflue into the Chaigas river which discharges the water through the deep chasm in the northwestern part of the Ka- tharo, into the Lassithi basin which lies $200 \mathrm{~m}$ below.

The Lassithi is completely encircled by mountains; it is kettle-shaped and there is no subaerial drain, the water being removed by a subterranean river. PSarianos (1961) studied the region, and concluded that the basin should be considered as a polje. It is shaped like a dish, and the bottom consists largely of crystalline schists. These are exposed in the middle of the basin, at the hill on which the village of Ay. Konstantinos is built. Only the rims of the basin consist of limestone.

The structure of the Katharo resembles that of the Lassithi. Wherever the subsoil of the Katharo becomes visible, it consists of strongly weathered flysch slates and sandstones. It is possible that in the younger Neogene climatic circumstances favoured the weathering of slates and schists rather than of limestones. In the Levka Ori of Western Crete, the schist mountains are still covered with a heavily eroded mantle of weathered material which can have a thickness of about 50 metres.

Outcrops of shales and schists within limestone regions thus were weathered more intensively than their calcareous surroundings. The mantle of loosened material produced in this way possibly was swept away during a pluvial period of the Pleistocene. It is known that (CreutzburG, 1958, 1961; Boexschoten, 1963) the large alluvial fans on the coasts of Crete are probably of Tyrrhenian age. The karst erosion had already started in the Neogene (Creutzburg, 1958).

\section{b. The Pleistocene sediments}

The Katharo contains a basin fill which consists of maximally $20 \mathrm{~m}$ of Pleistocene clays, clayey sands and angular gravel. The brook valleys are carved into, and sometimes through, the basin fill.

The gravels consist mainly of sandstone fragments; moreover vein quartz and red chert occur. Less numerous are limestone and steatite pebbles. Occasionally reworked Miocene shells are found.

The sands consist of rounded grains of micaceous shales in the coarser fractions; chert grains, steatite grains, diabase grains, some muscovite flakes occur also. Angular quartz grains are common in the coarser fractions and abundant in the finer.

The sediments contained no limestone grains with the exception of some limestone pebbles in the gravels and of the strata with fossils. In the latter, whitish calcareous concretions occur abundantly. Thus, solution of carbonates after the deposition of the sedi- 


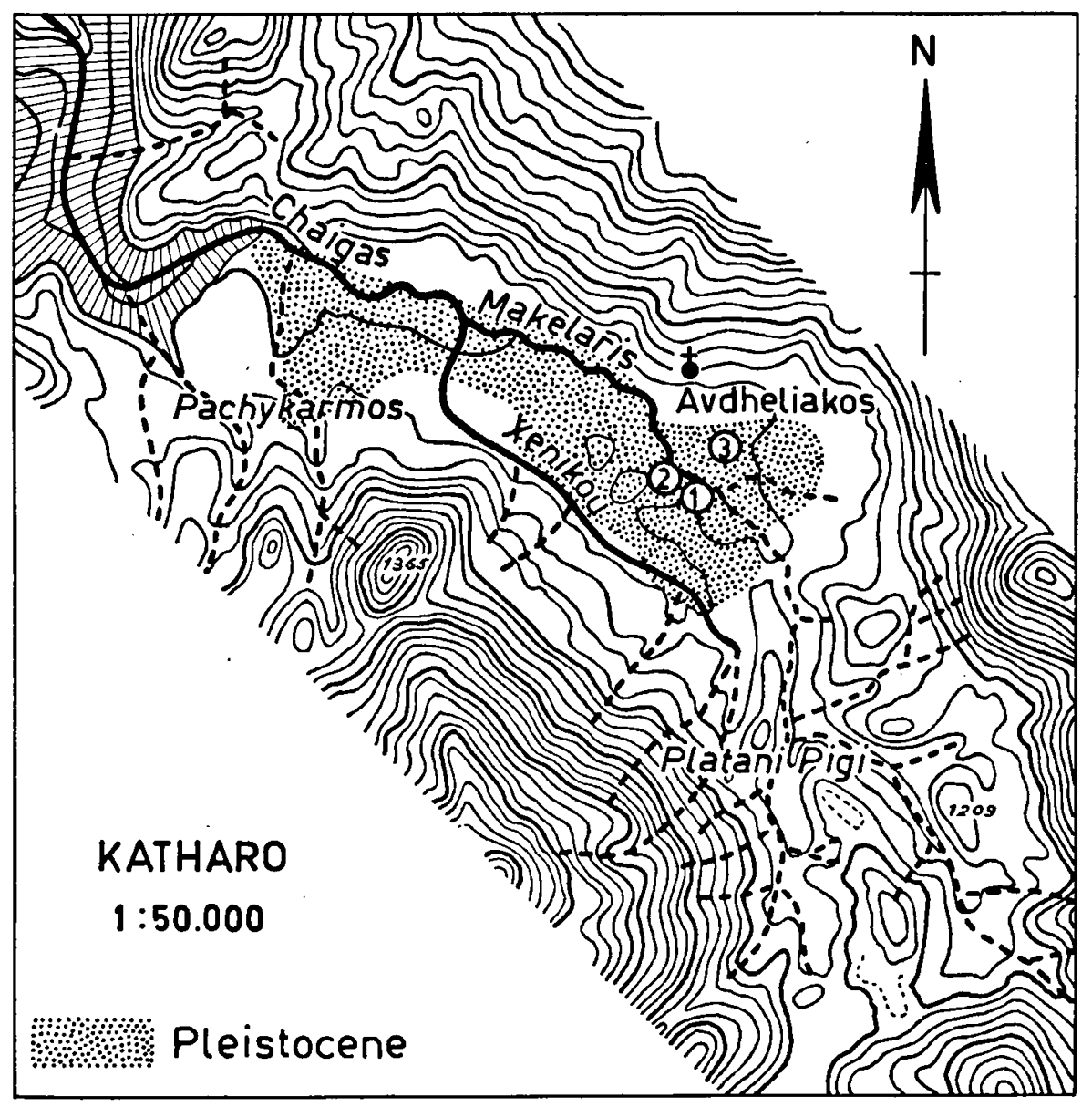

Fig. 1. Map of the Katharo basin.

ments has occurred. Decalcification may account for the vagueness of the lamination of the Katharo sediments. This process, moreover, has probably destroyed most of the fossils originally present in the sediments.

Mr. S. Bottema kindly investigated the pollen content of our samples. All but one proved to be sterile. Sample KR 625 from locality 2 contained some badly corroded pollen grains of Pinus, Quercus, Liguliflorae and Gramineae. Pinus is not present in the Katharo nowadays.

The fossil Hippopotamus was found on a small surface along the Makelaris brook, about $700 \mathrm{~m}$ south of Avdheliakos. In the left bank two erosion gullies are seen, along which the Pleistocene strata are exposed. The end of the eastern gully. was noted as locality 1 , the western as locality 2 ; both are indicated on the map (Fig. 1). Between both localities, crushed bone fragments were also found, indicating a continuous horizon in which the fossil bones were preserved. Our local informants did not know any other fossil bearing locality. Probably this was also the place where Miss Bate excavated her material; a widening of the erosion gully near the mouth possibly was caused by the digging, sixty years ago. Although Miss Bate (1905) writes about "a number of places" and "different depths", her description seems to comprise closely neighbouring trial trenches situated at different depths in one rather thick horizon.

Because of landsliding it is difficult to see a distinct profile at locality 1 . The stratigraphical succession is as follows.

Lowermost unstratified gray sandy clays with gravel are found, which contain calcareous concretions and Hippopotamus bones. These are covered by the same sediments, brick red and totally decalcified. Next is a well stratified level of sand and gravel 
with gully fills in the older sediments. Topmost there is a layer of beige laminated stony clay.

The last stratum is more differentiated about 200 m S from locality 1 . The profile shows here, from top to bottom:

$30 \mathrm{~cm}$ weathered beige clay

$20 \mathrm{~cm}$ brown clay

$30 \mathrm{~cm}$ beige clay

$5 \mathrm{~cm}$ black clay

$10 \mathrm{~cm}$ beige clay, underlain by brick red gravel and sandy clays identical to those at loc. 1 .

At locality 2 the profile is well exposed. From top to bottom:

$80 \mathrm{~cm}$ grey, laminated sandy clay with some pebbles $30 \mathrm{~cm}$ well-stratified brick-red sandy clay with gravel lenses; sample KR 625

$80 \mathrm{~cm}$ brown clay, unstratified, with angular pebbles $40 \mathrm{~cm}$ unstratified grey, calcareous clays with angular pebbles and bone fragments. Sample KR 624 .

Another good profile is situated near Avdheliakos, at the left bank of an erosion gully which empties itself into the Makelaris brook. It is indicated on the map (Fig. 1) as locality 3.

Lowermost reddish unstratified sandy clay is seen, which contains some pebbly levels. It is overlain by gray sands and gravels, showing diagonal cross bedding and gullying into the reddish clay. These sands are covered by pale gray and beige clays. Figure 3 shows the exposure.

The larger exposures are limited to the SE part of the Katharo, and they do not show the deeper parts of the Pleistocene. It is possible, however, to recognize four different levels which are present also in the profiles already described.
The lowermost level consists of unstratified gray to brown calciferous clay, containing angular pebbles and fragmented parts of Hippopotamus. It is covered by a zone of the same material, brick-red and completely decalcified. Then well-stratified sands and gravels are found, which are often brick-red too and gully into the underlying clay. These are in turn covered by well-stratified grey, beige or blackish variegated clays, sometimes containing pebbles also.

The sediments of the lowermost level have a peculiar grain size distribution, which is shown in the analyses (Fig. 4). The authors are indebted to Dr. H. J. Veenstra, who kindly provided these. The sediment can be called a diamicton. This term was coined by FurNT c.s. (1960a, 1960b) for poorly sorted terrigenous sediments that consist of sand and/or larger particles in a muddy matrix. Diamicton deposits can originate in several ways (FERRLans, 1963); boulder clays, mudflow deposits and turbidites are among them.

The diamicton of the Katharo can be explained as a deposit in a lacustrine environment, where relatively little sand was available. Extensive biological homogenisation and loss of structure owing to decalcification may account for the absence of stratification. The scarcity of sand is due to the nature of the source rocks that consist largely of flysch shale and slate with intercalated beds of sandstone and quartzite. Whereas the former desintegrated into clay, the latter mainly part into pebbles. These weathering products slowly filled the Katharo depression. At a certain time, sedimentation stopped and red-colouring took place.

Renewed flooding brought new gravel deposits in

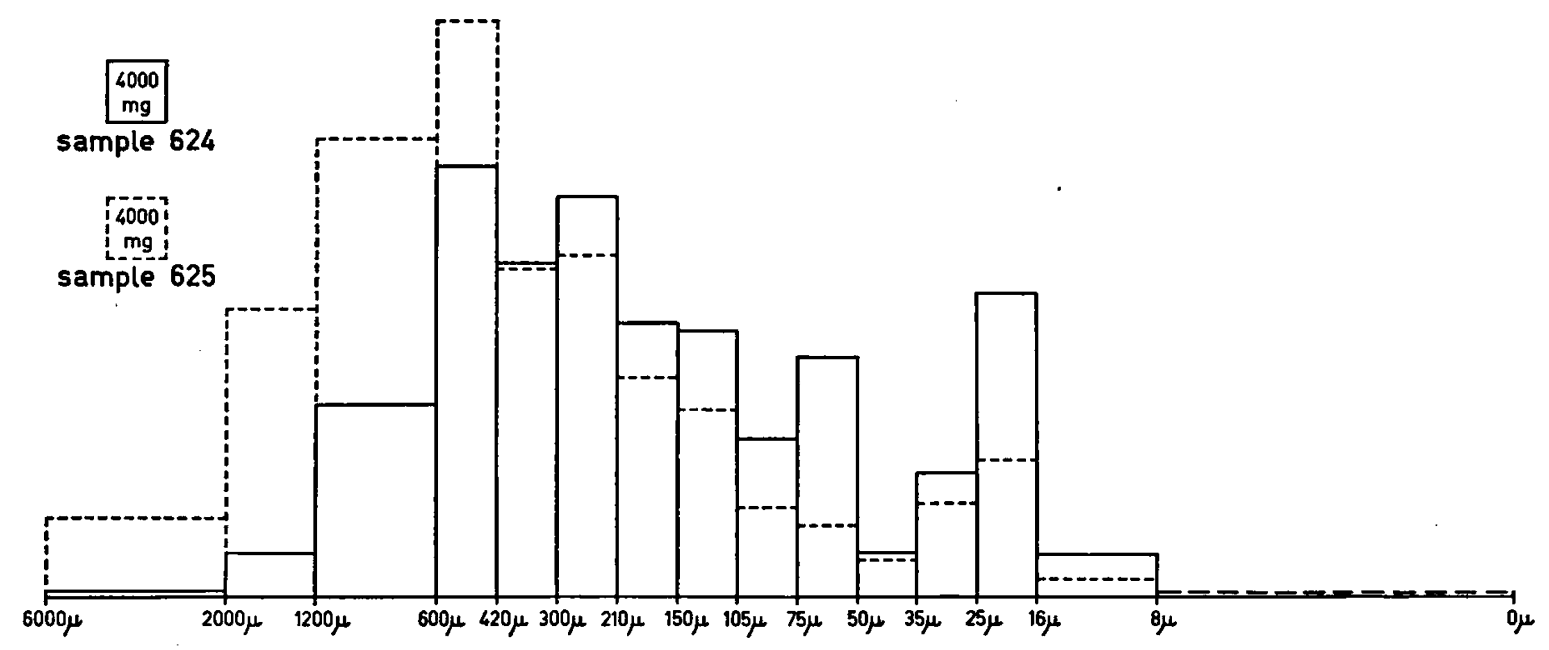

Fig. 4. Histograms of the grain size distribution in two diamicton samples (Katharo). 


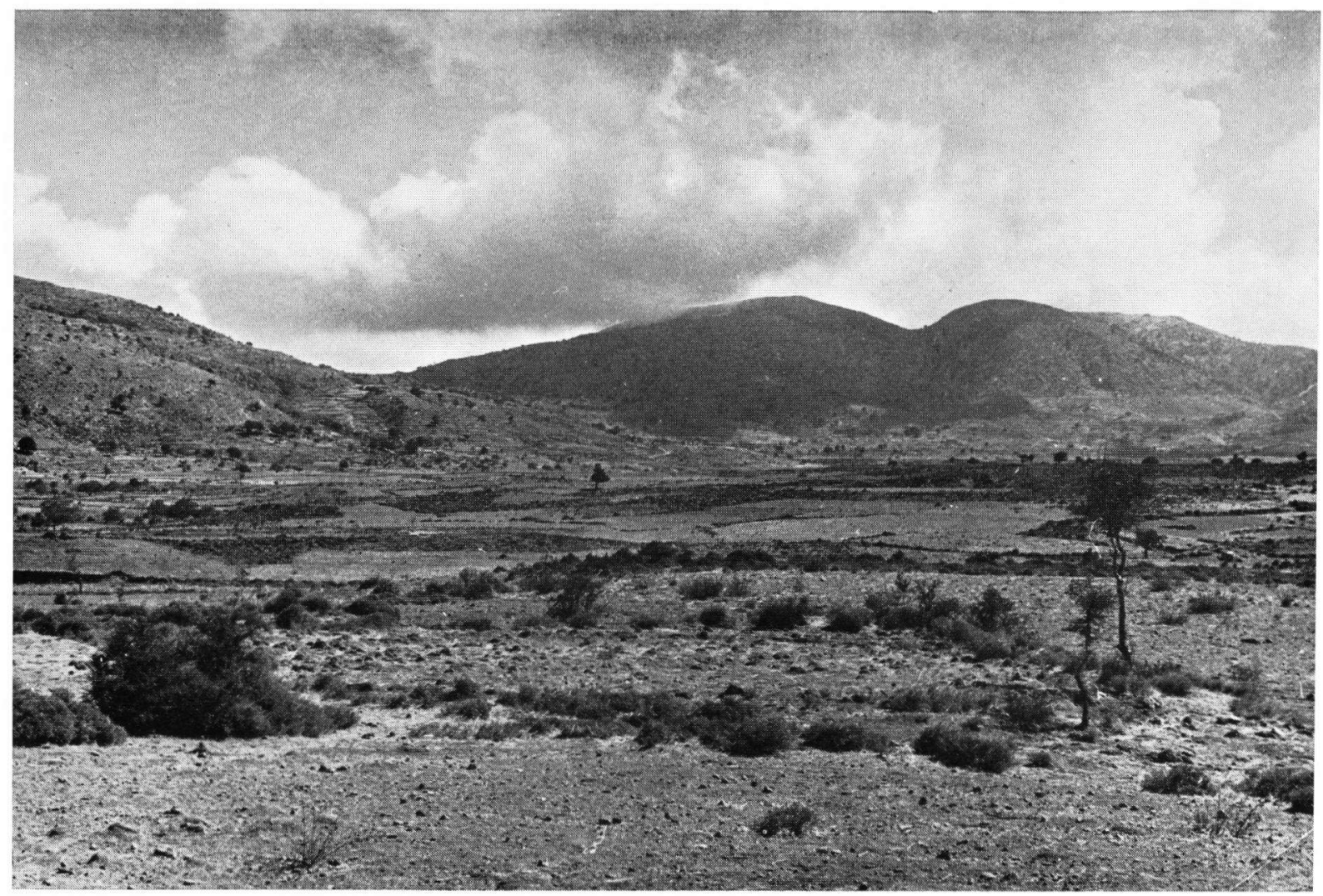

Fig. 2. Landscape of the Katharo.

Fig. 3. Profile in basin sediments, near Avdheliakos.

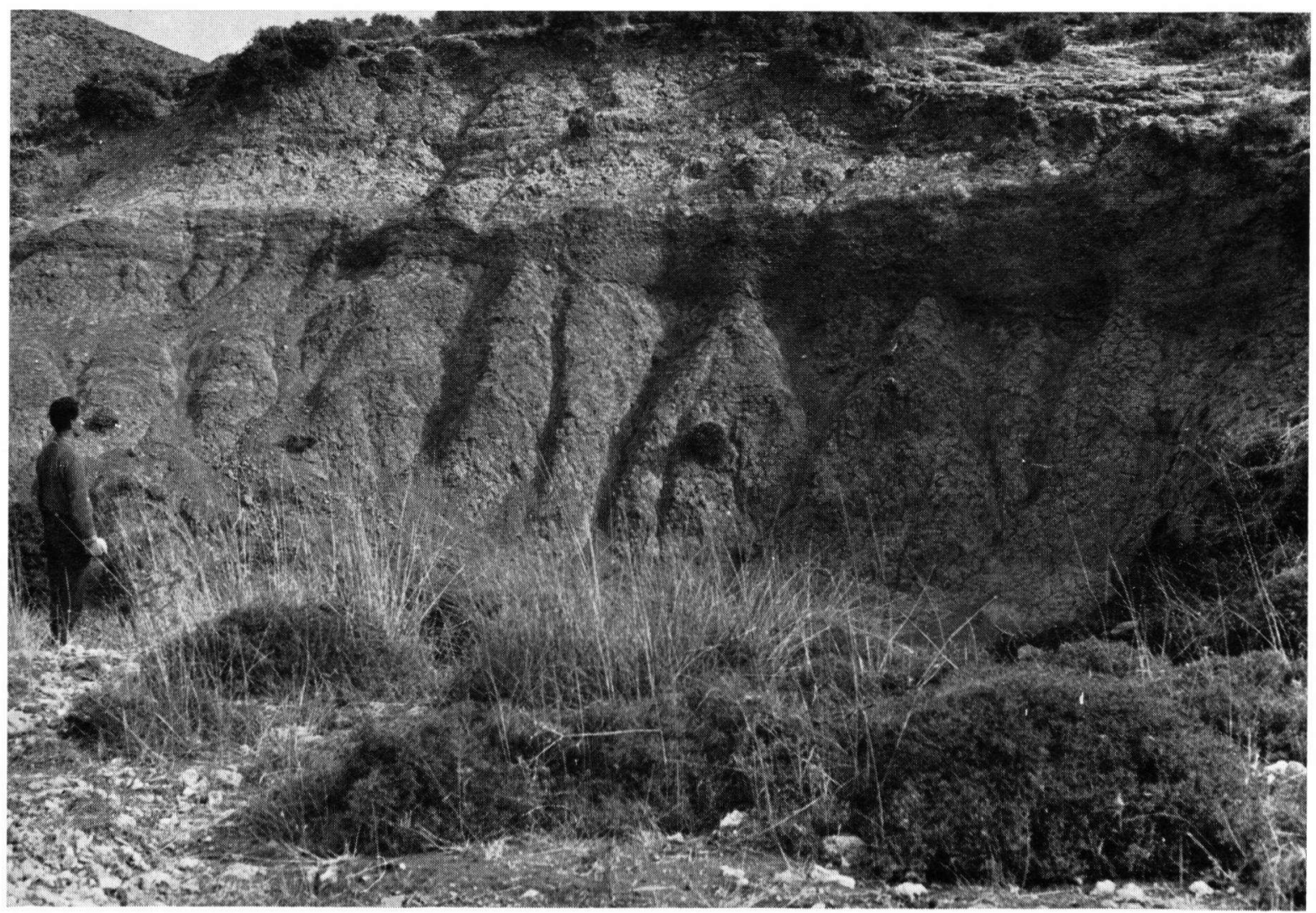


which red material was resedimented. Finally, during the drying out of the basin variegated clays were laid down.

The variegated clays are covered by a layer of about $1 \mathrm{~m}$ grey-coloured well rounded gravel, which is identical to the gravel deposits that are formed now in the beds of Makelaris and Xenikou. This gravel cover is related already to the present topography. If the strata with Hippopotamus are assigned to the Mindel-Riss or the Riss-Würm interglacials, (see also the paleontological part), these strata and the incision of the connected valleys can be dated in about the Late Glacial.

\section{PALEONTOLOGY}

\section{a. General remarks on the material studied}

Nearly all Hippopotamus remains dealt with in this study were collected by Miss D. M. A. Bate in the Pleistocene Katharo Basin (Crete). Some specimens were collected by the authors, during their field reconnaissance of the Katharo Basin. They are stored in the collections of the British Museum (Natural History), London. This collection comprises also an upper jaw fragment from a cave on the Cretan coast as well as extensive collections of fossil dwarf hippopotamuses from other Mediterranean islands, mainly brought together by Dr. Falconer, Miss Bate and Dr. Forsyth Major. The latter collections were studied for comparison with the Katharo material.

Some fossils of the Katharo hippo, preserved in the Paris Museum, were also studied. Recent material of H. amphibius and H. liberiensis was studied for comparison. This material is stored in the Zoological Mu- seum, Utrecht. Within the Katharo material, two states of preservation are discernable. The majority of the fossils has a brown colour, is light-weight and is not worn appreciably. These fossils are jaw fragments, isolated teeth, smaller bones and fragments of larger bones that are well-preserved occasionally. A minority is formed by greyish-blue, somewhat heavier and clearly worn fossils. This group consists only of isolated teeth and bone fragments. When the authors visited the Katharo, it turned out that the former occur in the Pleistocene sediments, whereas the latter are surface finds. However, their provenance is the same Pleistocene horizon.

\section{b. Methods of study}

The molars are described with the terms coined by Hoorjer $(1946,1950)$ and Gregory (1951). The lobes of the main cones were denominated according to their direction, following HoorJer (1950). The nomenclature is rendered in our Figs. 5 and 6.

Kuss (1957), and also Melentis (1965), reject the application of the Cope-Osbom terminology (Hooljer, 1946 and 1950, Grecony, 1951) for Hippopotamus teeth. The present authors, however, prefer the CopeOsborn denominations in this case, used in a purely descriptive sense. The terms applied by Kuss are considered more confusing and also complicated; they are not homonymous in different languages.

Several different measures were taken and are enumerated below. The length and the width of the molars were measured at the base of the molar. The width just above the cingulum was also measured. In this case, width paraconus/protoconus and meta-

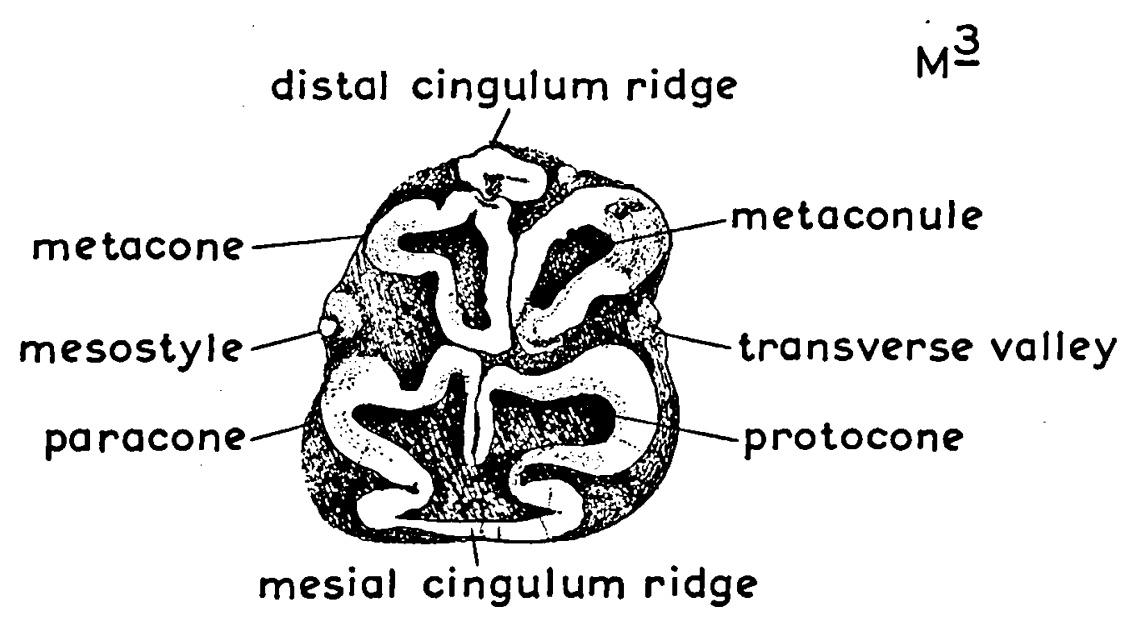

Fig. 5. Nomenclature upper cheek teeth. 


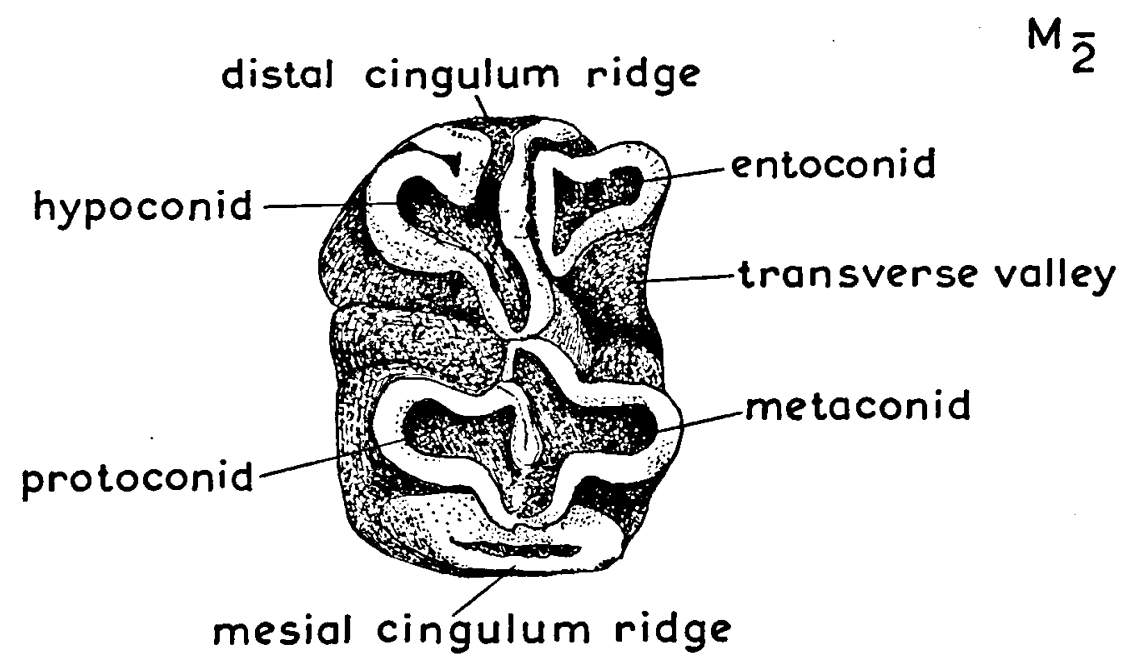

Fig. 6. Nomenclature lower cheek teeth.

conus/metaconule. The length and the width of the lower cheek teeth were measured at their base. The height was measured, in some unworn specimens, at the metaconid and the paracone. Other measures taken of the jaw and of miscellaneous parts of the skeleton are indicated in the text. In this study it is assumed that all the Hippopotamus material collected by Miss Bate in the Katharo, originally was preserved in one horizon. The authors could distinguish several fossiliferous localities when they visited the Katharo. Yet, all these proved to form part of one fossiliferous level, in which also Miss Bate's excavation site could probably be located (see under heading Pleistocene sediments).

The following abbreviations are used in the description:

BMNH $=$ British Museum (Natural History), London

MHNP $=$ Museum d'Histoire Naturelle, Paris

ZIU = Museum Zoological Institute, Utrecht

GIU = Geological Institute, Utrecht.

\section{c. Description of the Katharo Hippopotamus as a} new species

Class Mammalia Linnaeus, 1758

Ordo Artiodactyla Owen, 1848

Family Hippopotamidae Gray, 1821

Genus Hippopotamus Linnaeus, 1758

Species Hippopotamus creutzburgi nov. sp.

We consider the following descriptions of Cretan hippos (under different specific names) as belonging to our new species and as different from the specific type whose name they borrowed.
1845 Hippopotamus medius, Owen, R., p. 241

1847 Hippopotamus amphibius, Blainville, H. M. D., p. 102-104, Pl. VII and VIII

1867 Hippopotamus minor, Spratt, T. A. B., p. 386387

1868 Hippopotamus minutus, Falconer, H., p. 307

1885 Hippopotamus pentlandi, Lydekker, R., p. 289

1905 Pygmy Hippopotamus, Bate, D. M. A., p. 201

1921 Hippopotamus melitensis, Depéret, C., p. 164

1954 Hippopotamus melitensis, Leonardi, P., p. 191

1958 Hippopotamus pentlandi, Creutzburg, N., p. 31

1961 Hippopotamus melitensis, Viret, J., p. 953

1963 Hippopotamus cretensis, Thenius, E., and P. Hofer, (nomen nudum), p. 227

1965 Hippopotamus minor, Melentis, J. K., p. 428

1965 Hippopotamus pentlandi, Melentis, J. K., p. 428

1965 Hippopotamus melitensis, Melentis, J. K., p. 428

1965 Hippopotamus cretensis, Melentis, J. K., p. 430

TyPE LOCALITY: Katharo plain, Isle of Crete, Greece.

TYPE LEVEL: Pleistocene.

Denivatio nominis: after Prof. Dr. N. Creutzburg, whose studies on Crete are fundamental.

Diagnosis: Tetraprotodont Hippopotamus of small size $\left(\mathrm{M}^{1}-\mathrm{M}^{3}\right.$ about $10.2 \mathrm{~cm}, \mathrm{M}_{1}-\mathrm{M}_{3}$ about $11 \mathrm{~cm}$ ). Mandible rather delicate as compared with Hippopotamus amphibius. Astragalus and navicular articulating surfaces with considerable flexibility anteroposteriorly $\left(70^{\circ}\right)$. Tarsal and carpal bones with clear articulation surfaces on the medial and lateral sides. HolotyPE: Fragmentary upper jaw (British Museum collection number $\mathrm{M}$. 10286), with $\mathrm{P}^{4}-\mathrm{M}^{3}$ left and 
right with palatum in between. Figured on Plate I, Fig. 1.

Paratypes: Lower jaw (Plate II, Fig. 1) B.M.N.H. coll. no. M. 10287.

Right astragalus (Plate VI, Fig. 2) B.M.N.H. coll. no. M. 26153.

Right navicular (Plate V, Fig. 4) B.M.N.H. coll. no. M. 10301.

Left scapula (Plate V, Fig. 2) B.M.N.H. coll. no. M. 10294.

\section{Material:}

Upper jaw with $\mathrm{P}^{4}-\mathrm{M}^{3}$, left and right

Upper jaw with $\mathrm{DP}^{4}-\mathrm{M}^{2}$ left and $\mathrm{DP}^{3}-\mathrm{M}^{2}$ right

Upper jaw with $\mathrm{M}^{2} \mathrm{M}^{3}$ left and right

Upper jaw with DP4 $\mathbf{M}^{\mathbf{1}}$ left

Upper jaw with $\mathrm{M}^{2} \mathrm{M}^{\mathbf{s}}$ right

Three upper jaw canines, five upper jaw premolars, sixteen upper jaw molars

Lower jaw with $\mathrm{P}_{4}-\mathrm{M}_{3}$ left and right

Lower jaw with $\mathrm{DI}_{2}, \mathrm{DC}, \mathrm{DP}_{3}-\mathrm{M}_{1}$ left

Lower jaw with $\mathrm{DP}_{4}-\mathrm{M}_{\mathbf{2}}$ left

Lower jaw with $M_{1}-M_{3}$ left

Lower jaw with $\mathrm{M}_{2}-\mathrm{M}_{3}$ left

Lower jaw with $\mathbf{M}_{2}-\mathrm{M}_{3}$ right

Three lower jaw canines, two lower jaw premolars, nine lower jaw molars.

jome fragments of vertebrae.

Scapula: two fragments

Humerus: one distal fragment
Radiusulna: two proximal fragments and one distal Lunar: three specimens

Pisiform: two specimens

Metapodial: three specimens (Mc III, Mc IV, Mc V)

Phalanx: one first phalanx

Femur: one distal fragment

Tibia: one proximal, two distal fragments

Calcaneus: two fragments

Astragalus: two specimens

Navicular: two specimens

Cuneiform: one specimen

Metapodial: one Mt II, two Mt III, one Mt IV

Phalanx: three first phalanges.

\section{DESCRIPTION OF THE MATERIAL}

The measurements of the material are rendered on the Tables I-XXIV; all measurements are in $\mathrm{mm}$.

On the skull of Hippopotamus creutzburgi little can be said because of the paucity of the material. This consists solely of the palatum with $\mathrm{P}^{4}-\mathrm{M}^{3}$ which is the holotype of the species (Plate I, Fig. 1 and Table I). In Table I the index is given between the length of the teeth series $\mathbf{M}^{1}-M^{3}$ and the width of the palatum between $M^{2}$ left and $M^{2}$ right. The figures show that the Cretan Hippopotamus possessed a relatively narrow palatum. In this character it resembles much more $H$. minor than $H$. amphibius. The total length of the molar series $\mathbf{M}^{\mathbf{1}}-\mathbf{M}^{3}$ is longer than in $H$. liberiensis and $H$. minor, but shorter than in H. amphibius.

Table I. Upper jaw

\begin{tabular}{|c|c|c|c|c|c|}
\hline & $\begin{array}{c}\text { H. creutzburgi } \\
\text { Katharo (Crete) } \\
\text { B.M.N.H. } \\
\text { M } 10286 \\
\text { Type }\end{array}$ & $\begin{array}{c}\text { H. minor } \\
\text { Cyprus } \\
\text { B.M.N.H. } \\
\text { M } 9329\end{array}$ & $\begin{array}{r}\text { H. liberie } \\
\text { Liber } \\
\text { B.M.N.H. } \\
\text { 14/6-21 }\end{array}$ & $\begin{array}{l}\text { nsis } \\
\text { ia } \\
\text { Z.M.U. }\end{array}$ & $\begin{array}{c}\text { H. amphibius } \\
\text { Z.M.U. }\end{array}$ \\
\hline 1. length $M^{1}-M^{3}$ & 102 & 72 & 72 & 70 & 126 \\
\hline 2. width palate at $\mathbf{M}^{2}$ & 46 & 36 & 40 & 38 & 79 \\
\hline 3. index $1 / 2$ & 2.2 & 2 & 1.8 & 1.8 & 1.6 \\
\hline $\begin{array}{l}\text { 4. length } P \\
\text { width }\end{array}$ & $\begin{array}{l}19.7 \\
21.8\end{array}$ & - & $\begin{array}{l}12.1 \\
15.3\end{array}$ & $\begin{array}{l}15.0 \\
16.0\end{array}$ & $\begin{array}{l}24.0 \\
33.3\end{array}$ \\
\hline $\begin{array}{l}\text { 5. length } \mathbf{M}^{\mathbf{1}} \\
\text { width }\end{array}$ & $\begin{array}{l}28.0 \\
29.1\end{array}$ & $\begin{array}{l}19.8 \\
19.2\end{array}$ & $\begin{array}{l}17.6 \\
20.3\end{array}$ & $\begin{array}{l}19.9 \\
22.0\end{array}$ & $\begin{array}{l}41.0 \\
41.2\end{array}$ \\
\hline $\begin{array}{l}\text { 6. length } M^{2} \\
\text { width }\end{array}$ & $\begin{array}{l}37.0 \\
34.0\end{array}$ & $\begin{array}{l}25.0 \\
24.2\end{array}$ & $\begin{array}{l}26.3 \\
28.3\end{array}$ & $\begin{array}{l}25.0 \\
25.5\end{array}$ & $\begin{array}{l}49.8 \\
42.2\end{array}$ \\
\hline $\begin{array}{l}\text { 7. length } \mathbf{M}^{3} \\
\text { width }\end{array}$ & $\begin{array}{l}36.0 \\
33.1\end{array}$ & $\begin{array}{l}26.0 \\
25.0\end{array}$ & $\begin{array}{l}29.0 \\
27.2\end{array}$ & $\begin{array}{l}23.0 \\
25.0\end{array}$ & $\begin{array}{l}45.0 \\
41.0\end{array}$ \\
\hline
\end{tabular}


Table II. Upper canine

\begin{tabular}{|c|c|c|c|c|c|c|c|c|c|}
\hline & \multicolumn{3}{|c|}{$\begin{array}{c}\text { H. creutzburgi } \\
\text { Katharo (Crete) } \\
\text { B.M.N.H. } \\
\text { M } 10290\end{array}$} & \multirow{2}{*}{$\begin{array}{c}\text { H. melitensis } \\
\text { Malletta cave } \\
\text { (Malta) } \\
\text { B.M.N.H } \\
\text { R 49325-6 } \\
26.0\end{array}$} & \multirow{2}{*}{$\begin{array}{c}\text { H. cf. amphibius } \\
\text { Ghar Dhalam } \\
\text { cave (Malta) } \\
\text { B.M.N.H, } \\
\text { M } 4696 \\
40.3\end{array}$} & \multicolumn{2}{|c|}{$\begin{array}{l}\text { H. minor } \\
\text { Cyprus } \\
\text { B.M.N.H. } \\
\text { M } 9287\end{array}$} & \multicolumn{2}{|c|}{ 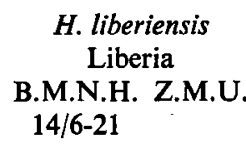 } \\
\hline 1. length & 20.0 & 18.5 & 22.7 & & & 16.3 & 16.0 & 20.0 & 25.0 \\
\hline 2. width & 25.0 & 24.7 & 28.0 & 33.5 & 46.6 & 23.0 & 22.5 & 29.5 & 35.0 \\
\hline
\end{tabular}

Table III. Upper premolars

\begin{tabular}{|l|ccccc|}
\hline & \multicolumn{5}{|c|}{ H. creutzburgi, Katharo (Crete), B.M.N.H. M 10293 } \\
\hline & $\mathrm{P}^{2} ?$ & $\mathrm{P}^{3}$ & $\mathrm{P}^{3}$ & $\mathrm{P}^{3}$ & $\mathrm{P}^{4}$ \\
1. length & 27.0 & 24.0 & 25.5 & 27.0 & 22.0 \\
2. width & 26.0 & 18.8 & 17.5 & 21.0 & 20.4 \\
3. height & 23.5 & - & 24.0 & 27.5 & 24.0 \\
\hline
\end{tabular}

Canines (Plate IV, Fig. 5, Table II)

The canines are less curved than those of $H$. melitensis (Plate IV, Fig. 6) and H. amphibius. The groove that is always present on their distal face, is relatively deep. It appears from the section that the canine is angular mesially; its general shape is oval and not triangular as in $H$. melitensis.

Second premolar upper jaw (Table III)

This tooth is conical; a cingulum is present at its distal side.

Third premolar upper jaw (Table III)

This tooth is monocuspid; a well-developed cingulum is present at its lingual, distal and mesial sides.
On this cingulum, tuberculae are sometimes present. The first three premolars are more complicated than those of $H$. minor, which are conical with weakly developed cingulum.

Fourth premolar upper jaw (Plate I, Fig. 1, Table III) The cingulum of this premolar is still more developed than in the preceding premolars. Although this premolar remains monocuspid, there are two lobes. One is seen at the distal side of the main cusp, and runs to the lingual side, the other runs from the mesial side of the tooth to linguo-mesial. The cingulum is strongly developed at the distal and the lingual side of the tooth. The fourth upper premolar is less complicated than that of $H$. amphibius and $H$. pentlandi

Table IV. $M^{1}$

\begin{tabular}{|c|c|c|c|c|c|c|c|c|}
\hline & \multicolumn{8}{|c|}{ H. creutzburgi, Katharo (Crete) } \\
\hline & \multicolumn{2}{|c|}{$\begin{array}{l}\text { B.M.N.H. } \\
\text { M } 10286\end{array}$} & \multicolumn{4}{|c|}{$\begin{array}{c}\text { B.M.N.H. } \\
\text { M } 10288\end{array}$} & $\begin{array}{l}\text { B.M.N.H. } \\
\text { M } 10294\end{array}$ & $\begin{array}{c}\text { M.H.N.P. } \\
3957\end{array}$ \\
\hline 1. length & 28.0 & 28.1 & 30.1 & 31.0 & 32.4 & 34.0 & 34.2 & 31.0 \\
\hline 2. width $\mathbf{P r}-\mathbf{P a}$ & 24.1 & 23.0 & 22.5 & 22.2 & 22.5 & 23.7 & 23.1 & - \\
\hline 3. width Me-M1 & 26.0 & 26.2 & 24.6 & 22.5 & 23.5 & 24.1 & 23.7 & 26.5 \\
\hline 4. width max. & 29.1 & 28.3 & 27.3 & 26.8 & 26.8 & 28.8 & 27.5 & 29.0 \\
\hline 5. height $(\mathrm{Pa}$.) & - & - & - & - & - & - & 29.0 & - \\
\hline
\end{tabular}


where several cusps are sometimes present. Three roots, as they occasionally occur in $H$. pentlandi and H. liberiensis, were not observed in our material.

First molar upper jaw (Plate I, Fig. 1; Plate III, Fig. 3, Table IV)

Most specimens are worn down. Protocone and paracone, metacone and metaconule are already fused at an early stage of wear. The lobes of the cusps to distal and mesial are less pronounced than in $\mathbf{M}^{2}$ and $\mathrm{M}^{3}$. The mesial cingulum ridge is well-developed. The cingulum makes up a small mesostyl at the buccal side of the transverse valley; at the lingual side of this transverse valley, on the base of the protocone, the cingulum forms little tubercles. The mesial width of the molar is always less than that at the distal side (see Table IV).

Second and third molars upper jaw (Plate I, Fig. 1; Plate III, Fig. 3, Table V and VI)

These two teeth are morphologically quite similar and, therefore, they are described jointly. The third molar is somewhat more narrow at the distal side than the second one. The distal cingulum ridge tends to develop as a cusp in $\mathrm{M}^{3}$. Paracone and protocone, metacone and metaconule tend to fuse when the teeth are well-worn. From para- and protocone lobes are directed distally; from metacone and meta- conule mesially. The latter are somewhat more distinct. The most prominent lobe is that running from the metacone to its mesial side; it touches the lobe from the paracone to its distal side. Another lobe runs from the protocone mesially; this lobe fuses in an early stage with the mesial cingulum ridge. The cingulum ridge is well-developed at the mesial and distal side of the tooth; it reaches to about half the height of the tooth. In the transverse valley, lingually a cingulum ridge is observed around the protocone; buccally often a distinct mesostyl has developed.

When upper molars of Hippopotamus creutzburgi are compared with those of other Hippopotami, the following differences are noted. The teeth are more hypsodont than those of $H$. minor and $H$. liberiensis (see Table I and VI: index length/height and index width/height). The enamel pattern, however, is somewhat simpler than that of $H$. amphibius and more complicated than that of the (lophodont) molars of $H$. minor and $H$. liberiensis. The size of the molars is intermediate between that of $\boldsymbol{H}$. liberiensis and the Maltese $\boldsymbol{H}$. melitensis.

Hippopotamus minor is a bit outside this group. The cingulum is only weakly developed; it runs as a string around the base of the molar. The lobes from the cusps are less developed, and therefore worn molars obtain a lophodont appearance (Plate III, Fig. 1 and 2).

Table V. $M^{2}$

\begin{tabular}{|c|c|c|c|c|c|c|c|c|c|c|c|c|}
\hline \multirow[b]{2}{*}{ 1. length } & \multicolumn{12}{|c|}{ H. creutzburgi, Katharo (Crete) B.M.N.H. } \\
\hline & 30.1 & 32.0 & 33.9 & 34.3 & 34.9 & 35.0 & 35.0 & 35.3 & 36.0 & 37.0 & 37.3 & 39.0 \\
\hline 2. width Pr-Pa & 29.0 & 29.2 & 29.5 & 30.7 & 29.9 & 29.7 & 30.7 & 29.1 & 29.0 & 30.5 & 30.9 & 30.7 \\
\hline 3. width Me-Ml & 26.3 & 27.0 & 28.0 & 28.9 & 27.5 & 28.2 & 30.0 & 27.0 & 26.3 & 29.1 & 28.2 & 28.5 \\
\hline 4. width max. cingulum & 31.8 & 37.2 & 34.1 & 34.8 & 35.2 & 35.0 & 37.0 & 33.1 & 31.0 & 34.0 & 36.5 & 35.3 \\
\hline \multirow{4}{*}{$\begin{array}{l}\text { 5. height }(\mathrm{Pa} \text {.) } \\
\text { index } 1 / 5 \\
\text { index } 2 / 5\end{array}$} & - & - & - & - & - & - & - & - & 36.8 & - & - & - \\
\hline & - & - & - & - & - & - & - & - & 0.98 & - & - & - \\
\hline & - & - & - & - & - & - & - & - & 0.79 & - & - & - \\
\hline & \multicolumn{3}{|c|}{$\underset{3955}{\text { M.H.N.P. }}$} & \multicolumn{4}{|c|}{$\underset{3957}{\text { M.H.N.P. }}$} & \multicolumn{5}{|c|}{ H. minor, Cyprus G.I.U. } \\
\hline 1. length & \multicolumn{3}{|c|}{39.0} & \multicolumn{4}{|c|}{38.0} & \multicolumn{3}{|c|}{22.5} & \multicolumn{2}{|l|}{20.0} \\
\hline 2. width $\mathrm{Pr}-\mathrm{Pa}$ & \multicolumn{3}{|c|}{31.3} & \multicolumn{4}{|c|}{28.0} & \multicolumn{3}{|c|}{20.5} & \multicolumn{2}{|l|}{17.8} \\
\hline 3. width Me-Ml & \multicolumn{3}{|c|}{29.5} & \multicolumn{4}{|c|}{27.5} & & 20.1 & & \multicolumn{2}{|l|}{19.8} \\
\hline 4. width max. cingulum & \multicolumn{3}{|c|}{39.0} & \multicolumn{4}{|c|}{33.8} & & 22.8 & & \multicolumn{2}{|l|}{21.3} \\
\hline 5. height (Pa.) & \multicolumn{3}{|c|}{ - } & \multicolumn{4}{|c|}{ - } & & 17.5 & & \multicolumn{2}{|l|}{-} \\
\hline index $1 / 5$ & \multicolumn{3}{|c|}{-} & \multirow{2}{*}{\multicolumn{4}{|c|}{-}} & & 1.3 & & \multicolumn{2}{|l|}{ - } \\
\hline index $2 / 5$ & \multicolumn{3}{|c|}{ - } & \multicolumn{2}{|c|}{ - } & & & & 1.2 & & \multicolumn{2}{|l|}{-} \\
\hline
\end{tabular}


Table VI. $M^{3}$

\begin{tabular}{|c|c|c|c|c|c|c|c|c|c|c|c|c|}
\hline & \multicolumn{9}{|c|}{$\begin{array}{l}\text { H. creutzburgi, Katharo (Crete) } \\
\text { B.M.N.H. }\end{array}$} & \multicolumn{2}{|c|}{$\begin{array}{c}\text { M.H.N.P. } \\
3956\end{array}$} & $\begin{array}{c}\text { H. minor } \\
\text { Cyprus } \\
\text { G.I.U. }\end{array}$ \\
\hline 1. length & 33.0 & 34.0 & 34.5 & 35.5 & 36.0 & 36.0 & 36.5 & 37.0 & 38.8 & 380 & 390 & 25.0 \\
\hline 2. width Pr-Pa & 29.9 & 31.0 & 30.8 & 29.2 & 31.7 & 31.2 & 31.3 & 31.7 & 33.2 & 33.8 & 30.5 & 21.0 \\
\hline 3. width Me-M] & 25.8 & 27.3 & 27.0 & 25.5 & 28.0 & 29.4 & 27.0 & 29.0 & 27.5 & 28.0 & 27.5 & 19.5 \\
\hline 4. width max. & 32.2 & 33.3 & 31.8 & 36.3 & 33.0 & 33.1 & 33.5 & 37.0 & 34.9 & 36.0 & 37.0 & 23.5 \\
\hline 5. height (Pa.) & 一 & 一 & 一 & 一 & - & 36.0 & - & 41.3 & - & - & 一 & 20.5 \\
\hline index $1 / 5$ & 一 & - & - & - & - & 1 & 一 & 0.9 & - & - & 一 & 1.2 \\
\hline index $2 / 5$ & 一 & - & - & - & - & 0.86 & - & 0.77 & - & - & - & 1.0 \\
\hline
\end{tabular}

The measurements, width paracone-protocone, metacone-metaconule above the cingulum and the maximum width along the cingulum, show the variability in thickness of the cingulum. The first two measures are rather constant, the third is not because of variability of the cingulum. This also has been the reason why in the index for hypsodonty (width/ height) the width paracone-protocone was chosen.

Deciduous dentition of upper jaw (Plate III, Fig. 3) The only $\mathrm{DP}^{4}$ preserved is very much worn. Paraand protocone, metacone and metaconule are connected with each other. The lobes of the main cusps are not pronounced, just as in the $\mathbf{M}^{1}$. There is a well-developed cingulum ridge.

Upper jaw molars from Kharoumes cave (Plate I, Fig. 2)

In the British Museum collection, there is an upper jaw fragment containing $\mathrm{M}^{2} \mathrm{M}^{3}$ (catalogued $M$ 10305) which was found by Miss Bate in Kharoumes cave,
Sitia, Crete. The molars are within the size range of the Katharo molars (see Table VI, VII, VIII); nor does their morphology present any difference.

\section{Lower jaw (Plate II, Fig. 1, Table VIII)}

Only one more or less complete mandible is preserved. The part posterior to the $\mathrm{M}_{3}$ on both sides is missing. Moreover, the incisors as well as $P_{2}$ and $P_{3}$ were broken off at their alveoli. The left anterior part, with the canine, is rather damaged.

The lower jaw of $H$. creutzburgi is less heavy than that of $H$. amphibius. This is inferred by the data on Table VII; the height of the jaw below $\mathrm{M}_{2}$, the length of the symphysis, the distance between the canini all are in relation considerably smaller than the corresponding measurements in $H$. amphibius. This slenderness of the jaw is found also in $H$. minor, $\boldsymbol{H}$. liberiensis and $\boldsymbol{H}$. lemerlei.

The lower jaw of $\boldsymbol{H}$. creutzburgi is tetraprotodont (Gruppo dell'Hippopotamus amphibius according to Leonard, 1948). There is a diastema between $P_{3}$ and $\mathbf{P}_{4}$.

Table VII

\begin{tabular}{|l|cc|}
\hline & \multicolumn{2}{|c|}{ H. creutzburgi, Kharoumes cave (Crete) } \\
& B.M.N.H. M 10305 \\
\hline & $\mathrm{M}^{2}$ & $\mathrm{M}^{3}$ \\
1. length & 35.3 & \pm 40.0 \\
2. width Pr-Pa & 30.0 & 33.0 \\
3. width Me-Ml & 26.2 & 28.5 \\
4. width max. & 35.0 & 36.5 \\
\hline
\end{tabular}




\begin{tabular}{|c|c|}
\hline 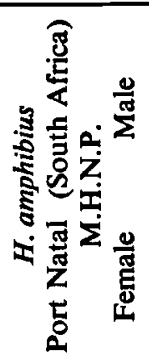 & 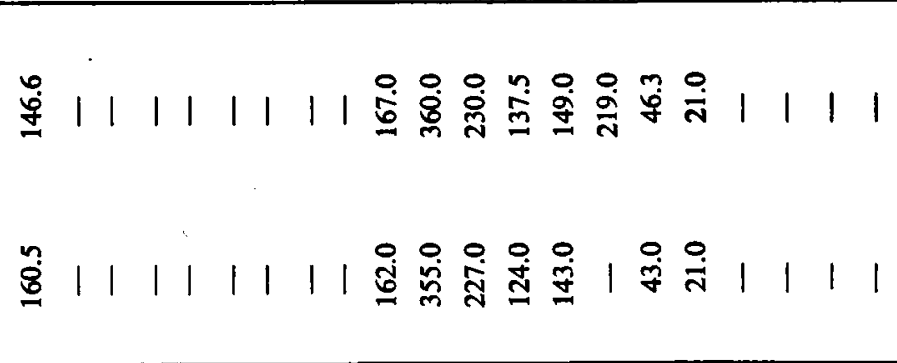 \\
\hline 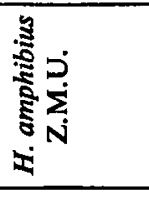 & 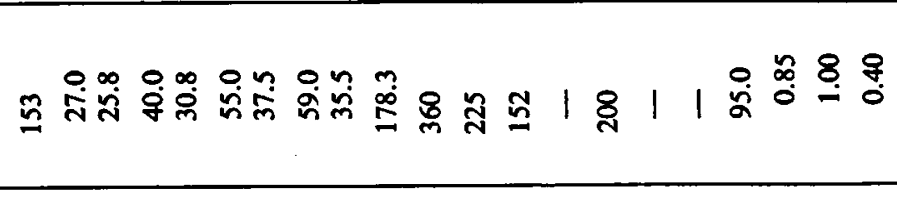 \\
\hline 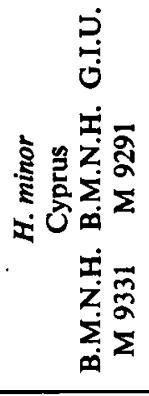 & 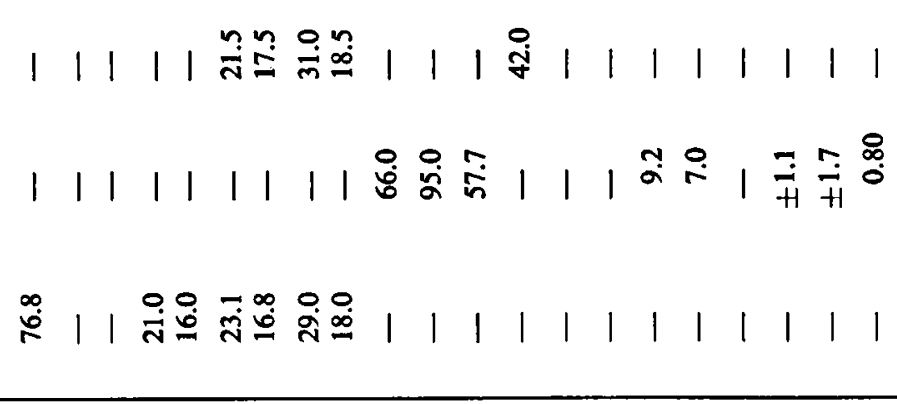 \\
\hline 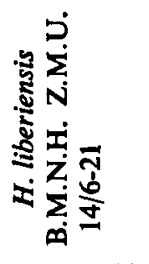 & 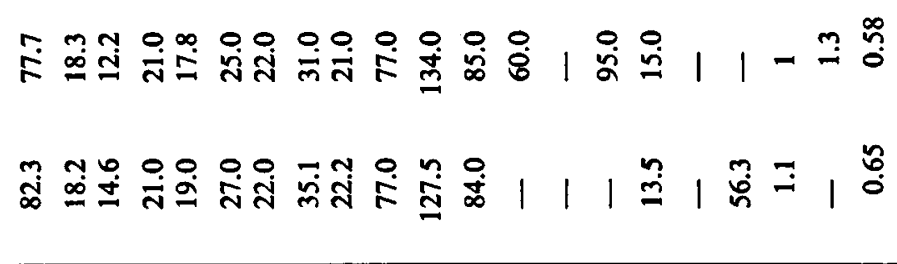 \\
\hline 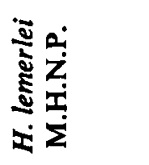 & 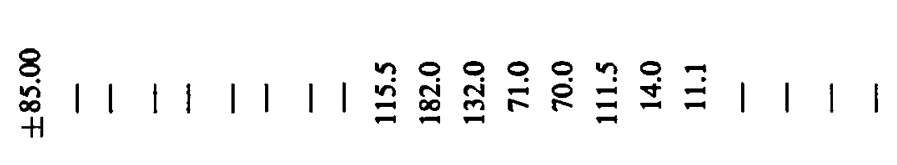 \\
\hline \multirow[t]{2}{*}{ 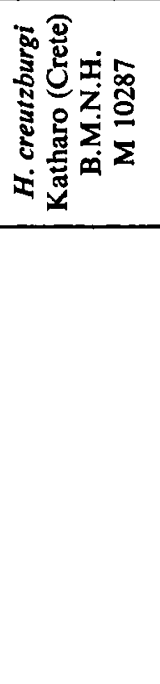 } & 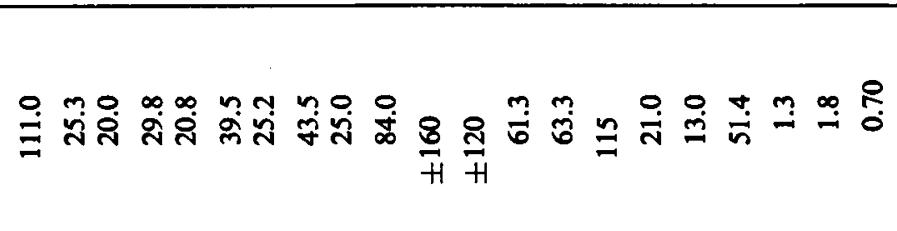 \\
\hline & 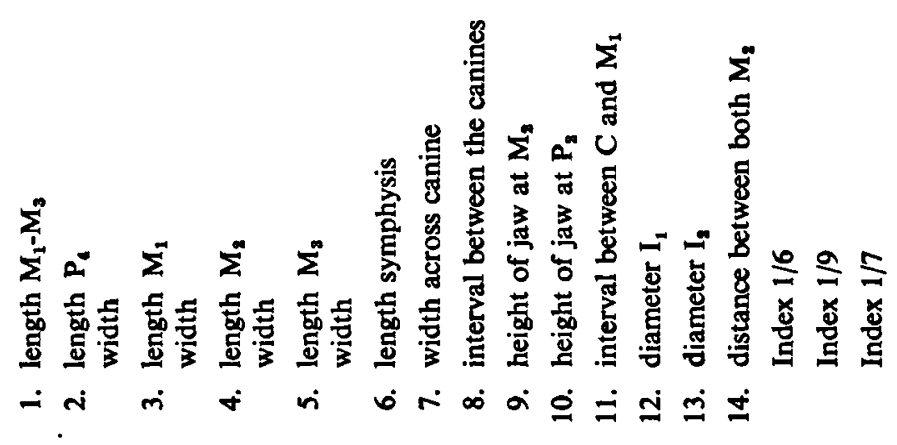 \\
\hline
\end{tabular}


Incisors (Table VIII)

These are nearly cylindric, and coated with a thin layer of enamel. The $I_{2}$ has a much smaller diameter than the $I_{1}$; the relation between both diameters is similar to that in $H$. amphibius.

Canines (Plate II, Fig. 1, Table IX)

The canine has an oval section that is curved inwards at the lingual side. The section of $H$. amphibius canines is more triangular; $H$. minor also shows this outline.

Fourth premolar lower jaw (Plate II, Fig. 1, Table $\mathrm{XI})$

The molar is monocuspid; the cusp is surrounded by a well-developed cingulum, particularly at its mesial and distal sides.

First molars lower jaw (Plate II, Fig. 1; Plate III, Fig. 4, Table XII)

Most specimens in the collection are rather worn. They show cusps which are connected with each other as well as with the distal and mesial cingulum ridges. The molar then consists of an enamel wall curving inward at the transverse valley; smaller indentations are visible at the junctions of the cusps with the distal and mesial cingulum ridge. There is a fragmentary, juvenile lower jaw in the British Museum collection (number $M$ 10296) which shows a still unworn $\mathbf{M}_{1}$. In this molar the lobes that descend

Table IX. Lower canines

\begin{tabular}{|c|c|c|c|}
\hline & \multicolumn{3}{|c|}{ H. creutzburgi, Katharo (Crete), B.M.N.H. M 10291} \\
\hline 1. length & 32.5 & 34.0 & 37.0 \\
\hline 2. width & 20.0 & 21.5 & 25.1 \\
\hline
\end{tabular}

Table X. Milk molars

\begin{tabular}{|l|c|c|c|}
\hline \multirow{2}{*}{} & \multicolumn{3}{|c|}{$H$. creutzburgi, Katharo (Crete), B.M.N.H. M 10296} \\
\cline { 2 - 5 } & $\mathrm{DP}_{8}$ & $\mathrm{DP}_{4}$ & $\mathrm{DP}_{4}$ \\
\hline 1. length & 19.5 & 32.2 & 37.0 \\
2. width & 11.0 & 15.8 & 17.5 \\
\hline
\end{tabular}

Table XI. $P_{4}$

\begin{tabular}{|l|c|c|c|}
\hline & \multicolumn{3}{|c|}{ H. creutzburgi, Katharo (Crete) } \\
\cline { 2 - 5 } & $\begin{array}{c}\text { B.M.N.H. } \\
\text { M 10293 }\end{array}$ & $\begin{array}{c}\text { B.M.N.H. } \\
\text { M 10287 }\end{array}$ & $\begin{array}{c}\text { B.M.N.H. } \\
\text { M 10293 }\end{array}$ \\
\hline 1. length & 24.0 & 25.3 & 27.5 \\
2. width & 20.0 & 20.0 & 20.0 \\
\hline
\end{tabular}

Table XII. $M_{1}$

\begin{tabular}{|l|cccc|}
\hline & \multicolumn{4}{|c|}{ H. creutzburgi, Katharo (Crete) B.M.N.H. } \\
\hline 1. length & 29.0 & 29.8 & 31.7 & 34.0 \\
2. width & 20.5 & 20.0 & 19.7 & 21.2 \\
\hline
\end{tabular}


Table XIII. $M_{2}$

\begin{tabular}{|c|c|c|c|c|c|c|c|}
\hline & \multicolumn{7}{|c|}{ H. creutzburgi, Katharo (Crete) } \\
\hline & \multicolumn{6}{|c|}{ B.M.N.H. } & \multirow{2}{*}{$\begin{array}{c}\begin{array}{c}\text { M.H.N.P. } \\
3958\end{array} \\
35.8\end{array}$} \\
\hline 1. length & 31.5 & 38.0 & 38.5 & 39.5 & 39.5 & 41.0 & \\
\hline 2. width & 25.0 & 25.0 & 28.0 & 28.0 & 25.2 & 28.0 & 25.8 \\
\hline
\end{tabular}

Table XIV. $M_{3}$

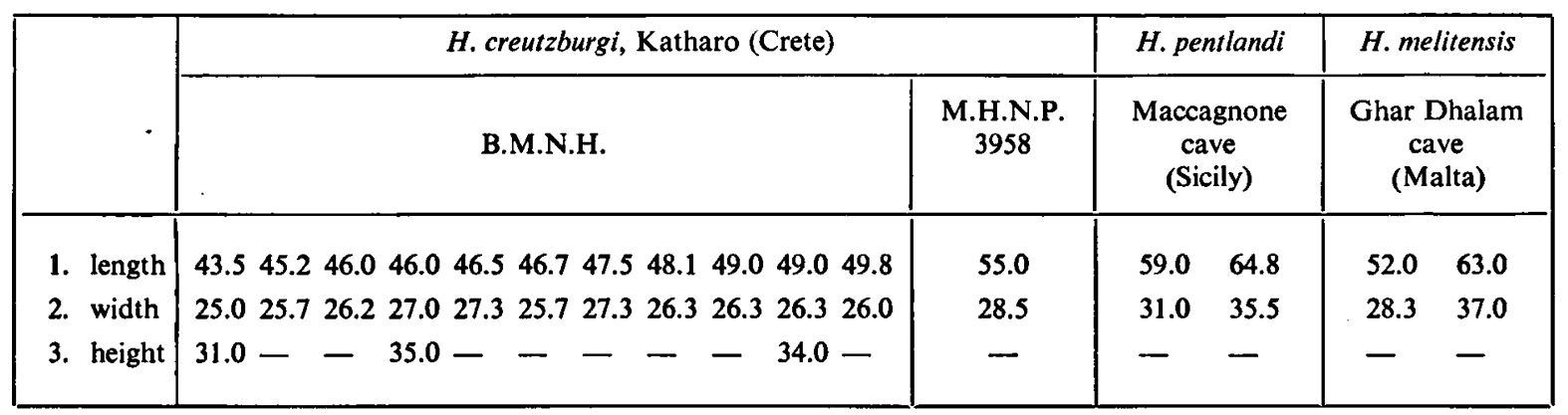

Table XV. Scapula

\begin{tabular}{|l|c|c|}
\hline & \multicolumn{2}{|c|}{ H. creutzburgi, Katharo (Crete) B.M.N.H. M 10294 } \\
\cline { 2 - 3 } & $\sin$ & dex. \\
\hline length glenoid cavity & 493 & 495 \\
width glenoid cavity & \pm 430 & 460 \\
\hline
\end{tabular}

from the cusps can be observed. The direction of these lobes is similar to that in $\mathbf{M}_{2}$ and $\mathbf{M}_{3}$ but less pronounced.

Second molars lower jaw (Plate II, Fig. 1 and 2, Table XIII)

There are clear-cut lobes running from the cusps. From the protoconid and metaconid they are directed mesially and distally; from the hypoconid and entoconid mesially, and in such a way that the lobe off the hypoconid touches on the distal lobe of the metaconid.

The mesial cingulum ridge is well-developed. It reaches till $2 / 3$ of the crown height and is seen as an isolated ridge on the mesial part of the molar, which fuses only at a later stage of wear with metaconid and protoconid. The distal cingulum ridge is less developed than the mesial and fuses with the hypoconid.

This pattern differs from that of the molars of the
Maltese hippopotamus. In the latter, the lobes of the protoconid and the hypoconid touch each other. The lobe from the protoconid in distal direction is thus more pronounced in the Maltese species (Plate II, 3).

Third molars lower jaw (Plate II, Fig. 1 and 2, Plate IV, Fig. 4, Table XIV)

These are identical with the $\mathrm{M}_{2}$, but for the talonid, that is enlarged with a cusp. Third lower jaw molars from Crete, Malta, Cyprus and Sicily are figured on plate IV, Fig. 1, 2, 3 and 4. The difference in size is remarkable. The lobes are simpler and the cingulum is less prominent in Hippopotamus minor. The Cypriotic molars are less hypsodont. Often a small cusp is seen distally from the hypoconid, which can reach till half of the crown height.

Deciduous dentition of lower jaw (Plate III, Fig. 4, Table X)

The left lower jaw ramus of a juvenile specimen, already mentioned, shows $\mathrm{DP}_{3}, \mathrm{DP}_{4}$ and $\mathrm{M}_{1}$, as well 
as the alveoles of the $\mathrm{C}$, the $\mathrm{DP}_{1}$ and the $\mathrm{DP}_{2}$. The $\mathrm{DP}_{3}$ shows a main cusp situated mesially, and two smaller cusps on its distal part.

The $\mathrm{DP}_{4}$ is trilophid; each loph consists out of two cusps. The distal cusps pattern is similar to that of the molars.

\section{Postcranial skeleton}

The larger bones were only fragmentarily preserved. Their good state of preservation, however, made detailed study of some morphological features feasible. The bones of manus and pes were preserved more completely.

\section{Scapula (Plate V, Fig. 2, Table XV)}

Just two specimens were found; only their distal parts were preserved, the spine was broken off.

In both examples, the tuber scapulae is very prominent. As can be seen on Plate V, Fig. 2, the tuber scapulae of $H$. amphibius is situated much higher than in $H$. creutzburgi. It functions as a point of attachment for the biceps brachii as well as for the elastic tendons that keep scapula and humerus together. It appears as if the shoulder of $H$. creutzburgi was reinforced in order to fix the shoulder and elbow in standing and to flex the elbow joints in walking.
Radius - Ulna

Only the proximal part of a radius-ulna has been preserved. The olecranon ulnae is broken off. The width of the radius is $66.2 \mathrm{~mm}$.

\section{Lunar (Table XVI)}

The facet for the unciform is larger than that for the magnum. The latter is triangular and not oblong as in $H$. amphibius, which has facets of about equal size. When the lunar of $H$. creutzburgi is sectioned laterally-medial, the facets for magnum and unciform lie in one straight line, whereas these facets are saddle-shaped in $\mathrm{H}$ : amphibius, clearly convex in a laterally-medial section. The section anteriorposterior of both facets is more concave in $\mathrm{H}$. creutzburgi than in $H$. amphibius. At the distally-medial side of the lunar, a facet for the cuneiform is present in the Cretan finds but absent in $\mathrm{H}$. amphibius. There are also distinct facets for the cuneiform on the lateral side above the facet for unciform. These are missing in $H$. amphibius. The proximal facet is also more distinct than in the recent species. The lunar transmits a large part of the weight of the body by way of the radius-ulna to the carpalia. It is probable that the differences in morphology of the lunar are correlated with functional differences, when Cretan

Table XVI. Lunar

\begin{tabular}{|c|c|c|c|c|}
\hline & \multicolumn{3}{|c|}{ H. creutzburgi, Katharo (Crete) B.M.N.H. M 10301} & \multirow{2}{*}{$\begin{array}{l}\text { H. amphibius } \\
\text { G.I.U. }\end{array}$} \\
\hline & dex. & $\sin$. & dex. & \\
\hline distal diam.ant.-post. & 34.2 & 31.5 & 34.0 & 42.0 \\
\hline distal width & 33.0 & 31.0 & 32.5 & 47.0 \\
\hline width fac. unciform & & & & \\
\hline a) ant. & 20.0 & 19.0 & \pm 21.0 & 25.0 \\
\hline b) post. & 18.5 & 18.0 & \pm 18.0 & 24.5 \\
\hline width fac. magnum & & & & \\
\hline a) ant. & 12.0 & 10.5 & \pm 10.0 & 20.0 \\
\hline b) post. & 18.0 & 18.0 & \pm 19.0 & 27.0 \\
\hline
\end{tabular}

Table XVII. Pisiform

\begin{tabular}{|c|c|c|c|}
\hline & \multicolumn{2}{|c|}{ H. creutzburgi, Katharo (Crete) B.M.N.H. } & \multirow{2}{*}{$\begin{array}{l}\text { H. amphibius } \\
\text { G.I.U. }\end{array}$} \\
\hline & dex. & dex. & \\
\hline 1. max. length & 55.0 & 53.5 & 62.0 \\
\hline 2. max. height & 28.0 & \pm 27.0 & 34.0 \\
\hline 3. max. width & 29.0 & \pm 27.0 & 28.0 \\
\hline
\end{tabular}


and recent $H$. amphibius are compared. The remarkable curvature of the facets for magnum and unciform in anterior-posterior sense in the $H$. creutzburgi lunar could point to larger flexibility of the carpus joint in anterior-posterior direction. On the other hand the clear-cut facet for the cuneiform indicates restriction of the flexibility of the carpus joint in medial-lateral direction. Both characteristics indicate that the carpus joints of $\boldsymbol{H}$. creutzburgi are better suited for walking, but less adapted for spreading the legs than in $H$. amphibius.

\section{Pisiform (Fig. 7, Table XVII)}

There is a striking difference between the pisiform of $H$. creutzburgi and $H$. amphibius. Although some variation occurs in the shape of those of $H$. amphibius these never attain the shape of $H$. creutzburgi. The length of the pisiform is relatively greater and the bone is more slender in the middle. The H. amphibius pisiform is more rectangular. The creutzburgi pisiform shows more surface sculpturing due to ligament and tendon imprints. On the medial side just posterior to the facet for the cuneiform a tuberosity is seen. There also is a tuberosity on the posterior part of the bone (see Fig. 7).

The pisiform of H. lemerlei (M.H.N.P., mounted skeleton) and that of $H$. liberiensis are more similar to the one of $H$. creutzburgi.

The function of the pisiform may be regarded as bone interposed in the course of the tendons of the flexors which enables it to act at a mechanised advantage. On the posterior border ligaments are attached. The differences between $H$. amphibius and $H$. creutzburgi pisiforms can be explained if we suppose that the tendons and carpal ligaments attached to this bone had a more important function in $H$. creutzburgi than they have in $H$. amphibius.

Metacarpus (Plate VII, Fig. 1, Table XVIII)

One well preserved third metacarpal was present. The proximal part of the bone protrudes laterally over the fourth metacarnal. more so than in $\mathrm{H}$. amphibius. The facets for articulation with the fourth metacarpal are therefore somewhat different. The proximal articulation surface also projects over the same surface of the fourth metacarpal.

One well preserved fourth metacarpal was present. The articulation surface with the proximal part of the Mc III consists of two facets. The one is about perpendicularly oriented, the other (below the first) is somewhat flexed inwardly. This causes the protruding of the Mc III over the Mc IV. It was observed that laterally the $\mathrm{Mc} \mathrm{V}$ is in contact with Mc IV over its entire length. These articulations can be interpreted as an indication, that the bones were packed tightly together. The distal part of the bones is somewhat damaged. Melentis (1965) describes a Mc IV from Crete, and states that the sagittal crest on the poste-

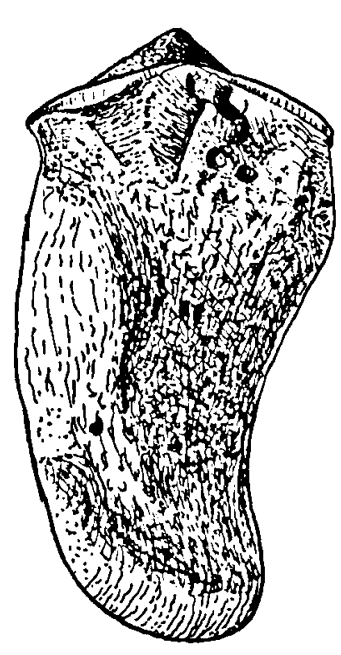

a

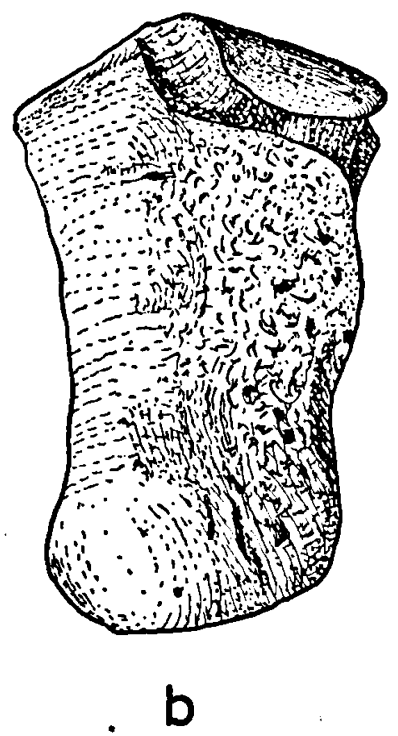

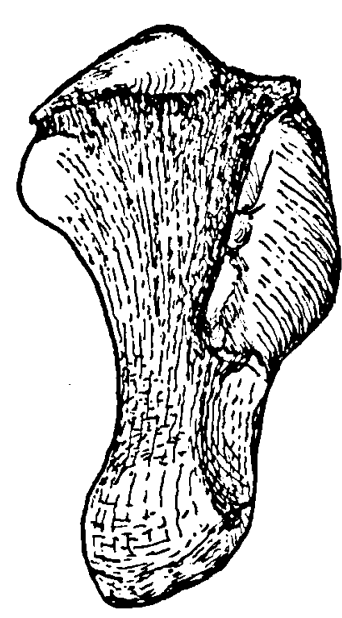

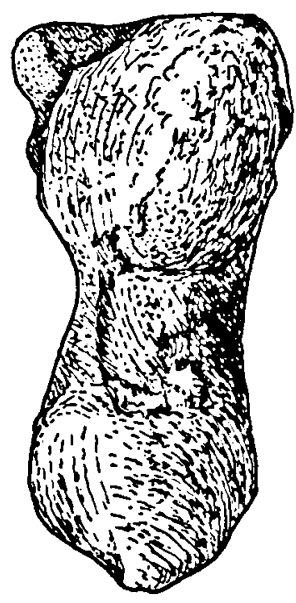

C

Fig. 7. Pisiform of $\mathrm{H}$. amphibius $(a, b)$ and $\mathrm{H}$. creutzburgi $(c, d)$ viewed proximally and laterally. 
Table XVIII. Metacarpus

\begin{tabular}{|l|c|c|c|c|c|c|}
\hline \multirow{2}{*}{} & \multicolumn{2}{|c|}{ H. creutzburgi, Katharo (Crete) } & \multicolumn{3}{c|}{ H. amphibius } \\
\cline { 2 - 7 } & $\begin{array}{c}\text { B.M.N.H. } \\
\text { M 10302 }\end{array}$ & \multicolumn{2}{|c|}{$\begin{array}{c}\text { B.M.N.H. } \\
\text { M 10302 }\end{array}$} & \multicolumn{3}{c|}{ G.I.U. } \\
\cline { 2 - 7 } & Mc IV sin. & Mc III sin. & Mc V dex. & Mc III sin. & Mc IV sin. & Mc V sin. \\
\hline & 74.0 & 86.0 & 62.5 & 142 & 124 & 97 \\
1. total length & 25.0 & 27.7 & 25.0 & 50 & 45.5 & 36 \\
2. width prox. & 28.0 & 30.1 & 26.3 & 45 & 43.7 & 36 \\
3. diam. prox. & 23.5 & 22.0 & 24.0 & 37.5 & 38.8 & 33 \\
4. width diaphysis & 14.5 & 14.0 & 18.3 & 20.8 & 23.2 & 25.5 \\
5. diam. diaphysis & 27.6 & 28.5 & 25.0 & 41 & 40 & 35 \\
6. width dist. & 24.0 & 26.2 & 25.0 & 35 & 35.8 & 37 \\
7. diam. dist. artic. surface & & & & & 4 \\
8. width at tubercules above & 31.0 & 28.2 & 30.5 & 4 & 43 & 41 \\
dist. artic. surface & & & & & \\
\end{tabular}

Table XIX. Phalanx I

\begin{tabular}{|c|c|c|c|c|c|c|c|c|}
\hline \multirow{2}{*}{ 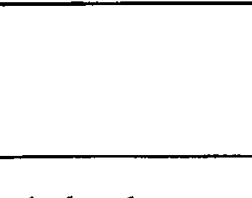 } & \multirow{2}{*}{\multicolumn{4}{|c|}{$\begin{array}{c}\text { H. creutzburgi, Katharo (Crete) } \\
\text { B.M.N.H. M } 10302\end{array}$}} & \multicolumn{4}{|c|}{ H. amphibius G.I.U. } \\
\hline & & & & & Mc III & Mc IV & Mt III & Mt IV \\
\hline 1. length & 39.0 & 41.0 & 41.5 & 41.0 & 59.0 & 56.0 & 61.5 & 58.0 \\
\hline 2. width prox. & 30.0 & 30.5 & 32.5 & 23.4 & 41.0 & 39.5 & 39.0 & 40.0 \\
\hline 3. diam. prox. & 25.1 & 24.1 & 25.0 & 24.5 & 32.0 & 33.8 & 34.0 & 38.8 \\
\hline 4. width middle & 24.3 & 23.2 & 26.0 & 20.4 & 35.5 & 34.0 & 34.0 & 32.8 \\
\hline 5. diam. middle & 14.5 & 13.0 & 14.3 & 16.3 & 20.8 & 22.0 & 22.0 & 20.2 \\
\hline 6. width dist. & 29.5 & 29.6 & 29.5 & 23.0 & 36.8 & 37.0 & 36.0 & 35.8 \\
\hline 7. diam. dist. & 16.0 & 17.0 & 16.3 & 15.0 & 23.0 & 25.0 & 22.7 & 24.0 \\
\hline
\end{tabular}

rior part of the distal articuiation surface is prominent (in $H$. amphibius barely visible). The sagittal crest prevents much lateral-medial movement of the phalanx. The more pronounced sagittal crest in $H$. creutzburgi indicates a restricted flexibility in medial-lateral direction when compared with $H$. amphibius.

\section{Phalanx (Plate VII, Fig. 4 and 5, Table XIX)}

It was difficult to determine the original position of the phalanges because no articulated specimens were found. Some differences with the phalanges of H. amphibius were observed. The latter are more regularly columnar, those of our species are typically more slender in the median part of the bone and, moreover, exhibit more clearly the ligamentary scars of the proximal part.

\section{CONCLUDING REMARKS ON THE MANUS}

The manus as a whole differs in the following aspects from that of $H$. amphibius.

1. Less movement is possible in medial-lateral direction

2. There is more flexibility in anterior-posterior direction

3. There is a more specialised muscle system.

The first is concluded from the following points.

a. The facets for magnum and unciform of the lunar of $H$. creutzburgi lie in one straight line lateral-medial, whereas these facets are saddleshaped in $H$. amphibius.

b. The clear cut well-developed facet for the cuneiform on the lunar. 
c. The facets on the Mc III and Mc IV show that these bones were more tightly packed together in $H$. creutzburgi than in $H$. amphibius.

d. Melentis (1965) observed, in a Mc III from a Cretan fossil Hippopotamus, a well-developed sagittal crest on the distal articulation surface. This prevents much lateral-medial movement of the phalanx.

The second point is inferred from the strong curvature of the facet for magnum and unciform in anterior-posterior sense.

The third point is inferred from the following:

a. The pisiform is relatively long and shows more surface sculpturing due to tendon imprints and attachment of the transverse carpal ligaments (Fig. 7).

b. The ligamentary scars of the phalanx are more clearly visible.

\section{Femur}

Only one right proximal fragment of a femur was present; trochanter major and a part of the head were broken off. The trochanter minor is (as compared with $H$. amphibius) relatively strongly developed. It forms the attachment of the ilio-psoas. This muscle helps to flex the hip joint and to rotate the thigh outwardly; maybe it was more prominent in $H$. creutzburgi, but we do not know enough of the variation in size of the trochanter minor in $\mathrm{H}$. creutzburgi to ascertain this. The diameter of the head of the femur is $54 \mathrm{~mm}$.

Tibia (Plate V, Fig. 1, Table XX)

Two distal fragments, and one proximal part of the tibia of $H$. creutzburgi were present amongst the material. When we compare the tibia of $H$. creutzburgi with that of $H$. amphibius, it appears that the proximal cnemial crest is much more prominent in the former. The same is noted when $H$. liberiensis is compared with $H$. amphibius.

The spine of the medial malleolus is strongly developed. This is evident also from the medial face of the astragalus, which shows a distinct facet for articulation with the malleolus.

\section{Astragalus (Plate VI, Fig. 2, Table XXI)}

Two right astragali were studied; one in excellent state of preservation, the other worn down. Facets were observed on the astragali of the Katharo hippopotamus that served the articulation of the calcaneum, the navicular and the cuboid as well as the trochlea talli. This bone differs in several respects from the astragalus of $H$. amphibius as well as from that of other Hippopotami.

The medial trochlea talli is less striking than the lateral, a common phenomenon in Hippopotami, but the difference between these trochleae is more im.portant in astragali of $H$. creutzburgi, $H$. pentlandi and $H$. minor than in those of $H$. amphibius. Moreover, a distinct facet at the medial side of the medial trochlea is present that runs into the caput where the part of the facet, serving the articulation of the navicular, protrudes medially. In H. amphibius, the facet of the trochlea at the medial side of the astragalus is not more than a string just alongside the roller. It has been remarked with the description of the tibia, that this facet corresponds with the medial malleolus spine of that bone. Hooujer (1950) describes a.o. astragali of Liberian and Javanese hippos.

Table XX. Tibia

\begin{tabular}{|c|c|c|c|c|c|}
\hline & \multicolumn{3}{|c|}{$\begin{array}{c}\text { H. creutzburgi Katharo (Crete) } \\
\text { B.M.N.H. M } 10299\end{array}$} & \multirow{2}{*}{$\begin{array}{c}\text { H. amphibius } \\
\text { Z.M.U. }\end{array}$} & \multirow{2}{*}{$\begin{array}{c}\text { H. liberiensis } \\
\text { Z.M.U. }\end{array}$} \\
\hline & right & right & left & & \\
\hline 1. distal width & 62.7 & 一 & 61.0 & 87.0 & 55.0 \\
\hline 2. distal diameter & 48.0 & - & 49.0 & 67.0 & 36.0 \\
\hline 3. minimal width & 40.0 & - & 33.8 & 55.0 & 29.0 \\
\hline 4. minimal diameter & 28.2 & - & 27.0 & 38.0 & 25.5 \\
\hline 5. prox. width & - & 94.0 & - & 一 & - \\
\hline 6. prox. diameter & - & 68.3 & - & 一 & - \\
\hline
\end{tabular}


Table XXI. Astragalus

\begin{tabular}{|l|c|c|c|}
\hline & $\begin{array}{c}\text { H. creutzburgi } \\
\text { Katharo (Crete) } \\
\text { B.M.N.H. } \\
\text { M 26153 }\end{array}$ & G.I.U. & $\begin{array}{c}\text { H. minor } \\
\text { Cyprus } \\
\text { G.I.U. }\end{array}$ \\
\cline { 2 - 4 } & dex. & sin. & sin. \\
\hline 1. height max. & 69.0 & 95.0 & 51.0 \\
2. height (lateral) & 63.0 & 80.9 & 46.8 \\
3. height (medial) & 57.3 & 64.5 & 39.0 \\
4. height (middle) & 59.5 & 82.0 & 41.5 \\
5. dist. width (in projection) & 61.8 & 80.5 & 39.8 \\
6. dist. width (articulation surface) & 55.0 & 69.8 & 35.0 \\
7. dist. diam. (articulation surface) & 31.5 & 49.0 & \\
8. width fac. navicular (below trochlea) & 28.5 & 39.0 & 16.5 \\
9. width fac. cuboid (below trochlea) & 25.5 & 35.5 & \\
\hline
\end{tabular}

These have a tuberosity on the medial side, immediately below the medial ridge of the trochlea. This tuberosity is absent in $H$. amphibius, but a comparable structure is present in $H$. creutzburgi. Here, the distal part of the bone protrudes, as can be seen also from the anterior.

The caput with the facet for the navicular protrudes medially outside the axis of the medial trochlea talli; these two lie in one plane in H. amphibius. The astragali of the BMNH Sicilian hippo also show this feature, but less so than in the Katharo hippo. At the lateral face of the astragalus, the upper facet for the calcaneum lies in one plane with the facet for the fibula. The sustentacular facet is very large. At the distal face, the crest between facet for cuboid and navicular is less pronounced than in $H$. amphibius. Lastly, the roundness of the facets covers a larger angle than in H. amphibius; in H. creutzburgi, this angle is about 180 degrees.
Calcaneum (Plate V, Fig. 3)

Two proximal fragments could be studied; they have a large facet for the astragalus.

Navicular (Plate V, Fig. 5, Table XXII)

One right navicular was available for study. It is higher than in $H$. amphibius. This is particularly clear at the side of the bone that articulates with the cuboid; here, a facet developed that does not occur in $H$. amphibius. The facet for the third cuneiform (on the distal side of the navicular) is also relatively large. When the bone is observed at its proximal face, it appears that the facet for articulation with the astragalus is more inflexed in anterior-posterior direction. This facet is more curved in medial-lateral direction in the navicular of $H$. amphibius.

Third cuneiform (Table XXIII)

Similar to the navicular bone, the cuneiform is also

Table XXII. Navicular

\begin{tabular}{|l|c|c|}
\hline & $\begin{array}{c}\text { H. creutzburgi, Katharo (Crete) } \\
\text { B.M.N.H. } \\
\text { M 10301 }\end{array}$ & G.I.U. \\
\hline 1. width & 37.0 & 44.1 \\
2. diameter & 47.0 & 59.0 \\
3. height (ant.) & 19.3 & 21.0 \\
4. height (post.) & 27.5 & 36.1 \\
\hline
\end{tabular}


Table XXIII. Cuneiform III (dex.)

\begin{tabular}{|l|c|c|}
\hline & $\begin{array}{c}\text { H. creutzburgi, Katharo (Crete) } \\
\text { B.M.N.H. } \\
\text { M 26156 }\end{array}$ & $\begin{array}{c}\text { H. amphibius } \\
\text { G.I.U. }\end{array}$ \\
\hline 1. diameter & 39 & 54 \\
2. ant. width & 28 & 36.5 \\
3. minimal ant. height & 15 & 19 \\
4. maximal ant. height & 12 & 11 \\
\hline
\end{tabular}

Table XXIV. Metatarsus

\begin{tabular}{|c|c|c|c|c|c|c|c|}
\hline & \multicolumn{4}{|c|}{$\begin{array}{l}\text { H. creutzburgi, Katharo (Crete) } \\
\text { B.M.N.H. M } 10302\end{array}$} & \multicolumn{3}{|c|}{$\begin{array}{l}\text { H. amphibius } \\
\text { G.I.U. }\end{array}$} \\
\hline & $\begin{array}{l}\text { Mt III } \\
\text { sin. }\end{array}$ & $\begin{array}{l}\text { Mt III } \\
\text { sin. }\end{array}$ & $\begin{array}{l}\text { Mt IV } \\
\text { dex. }\end{array}$ & $\begin{array}{l}\text { Mt II } \\
\text { dex. }\end{array}$ & $\begin{array}{l}\text { Mt II } \\
\text { sin. }\end{array}$ & $\begin{array}{l}\text { Mt III } \\
\text { sin. }\end{array}$ & $\begin{array}{l}\text { Mt IV } \\
\text { sin. }\end{array}$ \\
\hline 1. total length & 84.5 & 87.5 & 83.0 & 59.7 & 89.1 & 122.8 & 121.4 \\
\hline 2. width prox. & 31.5 & 32.2 & 25.2 & 20.2 & \pm 23.0 & 39.6 & 42.3 \\
\hline 3. diam. prox. & 38.2 & - & 31.5 & 23.8 & 32.0 & 49.1 & 53.3 \\
\hline 4. width diaphysis & 25.7 & 25.5 & 25.2 & 19.2 & 23.5 & 34.2 & 33.1 \\
\hline 5. diam. diaphysis & 16.3 & 16.3 & 16.0 & 18.7 & 27.0 & 23.4 & 23.0 \\
\hline 6. width dist. & 29.0 & 28.5 & 28.8 & 22.3 & 29.0 & 38.6 & 37.8 \\
\hline 7. diam. dist. art. surface & 26.7 & 25.5 & 25.5 & 23.7 & 32.2 & 34.7 & 34.7 \\
\hline $\begin{array}{l}\text { 8. width at tubercules } \\
\text { above dist. art. surface }\end{array}$ & 32.3 & 32.0 & 30.8 & 23.6 & 29.0 & 41.5 & 41.0 \\
\hline
\end{tabular}

higher than in $H$. amphibius. The articulation facets for cuboid and second cuneiform are also more distinct in $H$. creutzburgi. The articulation facets with third metacarpal and navicular are less inflexed than in H. amphibius.

\section{Metatarsal (Plate VII, Fig. 3, Table XXIV)}

On the Mt III laterally and Mt IV medial we can observe proximally only one well-developed facet of articulation. In $\mathrm{H}$. amphibius the facets of contact between these bones are clearly divided in two.

On the Mt II of $H$. creutzburgi the facet corresponding with the central cuneiform is relatively large. When we consider the metatarsals we note that the diameter of the diaphyse is small in relation to the width, when compared with those of $H$. amphibius which do have more the form of a pillar.

\section{CONCLUDING REMARKS ON THE TARSUS}

The tarsus as a whole differs from the of H. amphibius in four aspects, viz.:

1. less movement is possible in medial-lateral direction;

2. there is more flexibility in anterior-posterior direction;

3. the whole tarsus is relatively higher;

4. a larger part of the body weight is transmitted by the third metapode.

The first point is concluded from the following facts:

a. on the astragalus a distinct facet is found for the strongly developed medial malleolus on the tibia;

b. there are clear articulation facets between navicular and cuboid, third cuneiform and cuboid laterally and second cuneiform medially. 
These bones must have fitted more tightly together than in H. amphibius.

The second point is inferred from the strong curvature in anterior-posterior direction of the astragalus and navicular. Torsion of about $70^{\circ}$ must have been possible between astragalus and navicular. In H. amphibius this is $\pm 40^{\circ}$.

The third point follows from the relative height of the tarsalia of $H$. creutzburgi.

The fourth point results from the observation of a relatively large facet for the third cuneiform on the navicular. A large part of the body weight is transmitted by way of the tibia-astragalus-navicular-third cuneiform directly on to the third metatarsal bone. In H. amphibius this load is carried in a larger degree by second cuneiform and second metatarsal bone.

\section{d. H. creutzburgi nov. sp. as compared with other recent and fossil Hippopotami}

\section{SIZE}

$H$. creutzburgi is larger than $H$. minor from Cyprus and $H$. liberiensis, but smaller than the fossil Hippopotami from the Mediterranean islands Sicily and Malta (Table XIV and II).

\section{LOWER JAW}

The lower jaw is tetraprotodont and thus comparable to that of the recent $H$. amphibius and of the fossil $H$. minor, $H$. melitensis, $H$. antiquus (H. major), $H$. pentlandi and $H$. lemerlei. The $I_{2}$ is smaller than the $I_{1}$. This relation is similar to that in $H$. amphibius, melitensis, antiquus and pentlandi. H. lemerlei and minor possess two incisives which are about equal in size. The width of the mandible at the canines, the symphysis and the height of the jaw are in $H$. creutzburgi $H$. minor and H. liberiensis considerably less when compared with $H$. amphibius (Table VIII) and also with the large size fossil hippos according to data from Leonardi (1948), Kuss (1957) and ReYNoLDS (1922).

\section{MOLARS}

The morphology of the teeth of $H$. creutzburgi is in general like that of the fossil Hippopotamus of the mainland, as we may conclude from specimens figured from Valdarno (Leonardi, 1948), Peloponessos (Melentis, 1965), Rhein (Kuss, 1957), Barrington (REynolds, 1922). The pattern of the teeth of $H$. minor is less complicated and does not show a close relation to $H$. creutzburgi (Plate III, Fig. 1, 2).

\section{POSTCRANIAL SKELETON}

The postcranial parts of $H$. creutzburgi show striking differences with those of $H$. amphibius.

The tuber scapulae of the animal from Crete is more prominent and situated more distally than it is in H. amphibius and H. a. major (LeONARDI, 1948) (Table VI, Fig. 1).

H. liberiensis and also H. hipponensis (STRöMER, 1914 , p. 15, Fig. 3) show more resemblance to the fossils from Crete.

The distal articulation surface of the lunar is more concave in anterior-posterior direction than in H. amphibius.

The same can be said of the proximal articulation surface of the navicular. The distal articulation surface of the astragalus is more rounded antero-posteriorly. The tarsal and carpal bones of $H$. creutzburgi show clear facets on the lateral and/or medial sides which are indications of a tight contact. In H. amphibius and also $H$. pentlandi the facets are less clear or even missing.

It may be concluded from the preceding, that the skeletal features of $H$. creutzburgi place this species apart from the other hippopotami. On the other hand, its dentition suggests a narrow relationship with $\boldsymbol{H}$. amphibius. As the dentition is a rather conservative character because it does not alter as rapidly as skeletal features, the present authors consider this conclusive evidence for the supposition that $H$. creutzburgi arose from an isolated population of H. amphibius.

As Hippopotamus creutzburgi arose as a H. amphibius branch specialised for Cretan circumstances, it is very improbable that this form ever spread in other areas. More or less comparable species with similar (but not identical) features arose on other Mediterranean islands. In the past, all of these were brought together under one name either as $H$. minor or as $H$. melitensis. This denomination would imply a relationship between Cretan, Maltese and Sicilian hippos that never existed. Here, in addition to the morphological observations, paleogeographic data should be considered in delineating the several dwarfed Hippopotamus stocks.

A similar case arises when the distribution of the pygmy Megaceros found on Crete is studied. Kuss (1965) cites this form from Crete as well as Sardinia. It seems highly improbable that the Sardic and the Cretan deer ever were connected by intermediate populations. Instead, both arose probably wholly independently through isolation from the large mainland stock of megacerid deer. 
Even when the Cretan and the Sardic specimens would seem totally identical in a morphological sense, they can evidently impossibly be as closely related as a common specific name would suggest.

\section{DISCUSSION}

\section{a. The living Hippopotami}

It is most likely that the ancestry of Hippopotamus creutzburgi belonged to the group of $\boldsymbol{H}$. amphibius. For a paleoecological appraisal of the Cretan hippo fossils, it is necessary to summarize the main data on the mode of life of recent hippos. The most thorough investigation of hippo habits was published by VerHEYEN (1954). He surveyed populations in the easternmost part of the Congo. Additional data were published by Hedicer (1953), Grzimex (1956) and Bere (1959), who also studied hippos from the mid-African great lakes region.

Hippopotamus amphibius is not of a roving disposition; it is attached to its chosen territory. The habitat includes shallow water, as a resting place and as a refuge from the heat in the day-time. Swiftly running water is not suitable, as young hippos could be washed away by it. Moreover, the soles of the feet of $H$. amphibius are rather tender. When the animal is foraging, it places its feet carefully, walking slowly in order to avoid such obstacles as tree roots, stones, dead branches, skeleton parts, etc. It is probable that the stony bottoms of swiftly running rivers are too rough for hippo feet. The males each have their territory in the water, whereas females and their young offspring gather on sandbanks, marshy natural meadows on islets or level open places at the water side. Such places are indispensible for the Hippopotami; when a river flows slowly through a dense forest and open places do not occur, these animals do not settle there.

Territorial fights occur frequently amongst hippos. In fact, they are their own worst enemy as these fights sometimes end in the killing of one of the participants. Hippopotamus young sometimes are attacked by lion, hyena and crocodile, but it seems that predation by other animals is insignificant as a mortality cause.

When the animals are feeding, territorial fights are temporarily postponed. Feeding consists in the very thorough grazing of natural meadows by night. The animals eat exclusively grass of about $\mathbf{4 0}$ kilograms dry weight per day. As the meadows often lie some distance away from the water refuge (sometimes three kilometres from it) the animals make paths of about $65 \mathrm{~cm}$ width leading to the feeding place. As these paths are used for a long time, they are trodden out; some have sunk $1.3 \mathrm{~m}$ deep into the soil. When a region supports too large a number of hippos, soil erosion is caused both by these paths and by overgrazing. This hippo problem was dealt with by BERE (1959). It seems that each hippo needs at least seven hectares of pasture.

Hippopotamus amphibius has few enemies. Crocodiles are chased away; hippos and crocodiles do not occur in the same locality, presumably because the latter need sandy beaches for the laying of their eggs. These beaches are occupied by the hippo female clusters that do not permit crocodiles to intrude. Leeches are often found on hippos; perhaps they necessitate the "sunbathing" of the animals at daytime.

There is far less known of Hippopotamus liberiensis than of Hippopotamus amphibius, and this is caused by the solitary ways of this animal. Some data are found in publications by BütTIKofer and SALA (1883) and DeKeyser (1954). Even its distribution is poorly known, but it seems to be restricted to the southern coast of West Africa.

The animal is only half as long and high as the common hippo; male specimens of $H$. amphibius weigh about $1500 \mathrm{~kg}$ (females $1400 \mathrm{~kg}$ ), but the pigmy hippopotamus weighs only about $250-275 \mathrm{~kg}$. H. liberiensis is solitary or occurs in pairs; it has large territories, and it roams about only during the night. Its habitat is dense forest; it is not as linked to rivers and lakes as $\boldsymbol{H}$. amphibius is. Its food consist of soft leaves and the like, but nothing much is known thereof.

b. Morphological differences between $H$. amphibius and $H$. creutzburgi, and their significance

The morphology of the Cretan dwarf hippo was discussed in the preceding chapter. The most striking difference between the extinct Cretan hippo and the recent $H$. amphibius is the difference in size. The Cretan hippo is much smaller, and it is one of the many examples of nanism occurring on islands.

The functional meaning of smaller body size could be:

1. proportionally larger body surface, and therefore increased heat exchange with surrounding air or water;

2. decrease of necessary diurnal food quantity;

3. greater mobility; 
4. better adaptation to small places of shelter;

5. shorter period of pregnancy, and therefore larger production of young animals;

6. reduction of the area of the territories.

The head of Hippopotamus creutzburgi is proportionally smaller than that of $\boldsymbol{H}$. amphibius. The lower jaw is less outwardly projecting. This feature could be linked to the decrease of the body size, rather than to specialized functions. The surface of attachment of a muscle decreases more rapidly than the bulk of a muscle, when the size of an animal decreases. The molars are hypsodont and the cingulum is proportionally well developed when compared with $H$. amphibius. This has clearly a functional meaning when only hard food is available, that tends to wear away the teeth more quickly.

The tuber scapulae is strongly developed and forelimb musculature is thus better adapted to walking and climbing in rough environments. The same explanation can be given for the more flexible way in which the bones of the feet articulate (astragalus, carpalia and tarsalia) in anterior-posterior direction. Lateral-medial movement of the joints is, however, thereby impaired.

\section{c. Manner of life of Hippopotamus creutzburgi on Pleistocene Crete}

The island of Crete does not fulfil all requirements of present-day hippos. Lakes are scarce, large rivers are absent. Much of the island consists of barren limestone rocks that were already karstified in the upper Tertiary. Generally the soil is stony. The dwarf Hippopotamus occurred in the Katharo, which is now covered each year with snow. This fact suggests that the Katharo hippopotamus lived in that high mountain basin during an interglacial; in a glacial these altitudes would be covered with snow almost all the year round. Were this interglacial not appreciably warmer than the present, hippos could not have lived in the Katharo all the year round. In that case they would have visited the mountain regions in summer only, and lived in the lowlands during the winter. This would have meant migration along very rough, stony hillsides, as the Katharo belongs to a system of karst depressions without subaerial outflow. Moreover, the bottoms of the torrents on the slopes of the Dhikti mountains are very stony. That the animal occurred also in the lowlands is proved by the finds of Miss Bate (1905) in caves at Melato and Kharoumes, quite near the sea-shore.

All this would not be feasible for the recent $H$. amphibius. The latter is more or less sedentary; the tenderness of its feet precludes ramblings through mountainous regions. The morphological differences of $H$. creutzburgi and $H$. amphibius are readily explained by adaptation to the Cretan landscape.

There remain unsolved points. It is questionable, for instance, how the dwarf hippos lived in the caves near the sea-shore. Unluckily enough the fossil material of these occurrences is very scanty up till now; the only Cretan coastal find we could study was found by Miss Bate at Kharoumes, Eastern Crete.

The caves with Hippopotamus fossils hitherto discovered on Crete (Melato, Kharoumes) do not contain other fossil mammals such as the deer and elephants described by various authors. It is highly unlikely that Hippopotamus was the only mammal on Crete at any time, and it is difficult to understand how a bone deposit brought together by subterranean streams could consist of skeletal elements of widely varying size belonging to only one species. This phenomenon is not restricted to Crete alone; to judge from Falconer (1860) it occurs on Sicily also.

It seems much more probable that the Hippopotamus creutzburgi actually lived in these caves, and that it chased off intruders that desired to share their shelter just as Hippopotamus amphibius turns away crocodiles in its African territories. Caves were the only shelter against heat in the coastal region, whereas in the Katharo a lake could serve.

An interesting problem to be studied if such cave Hippopotamus fossils are investigated is whether these all belonged to juveniles and female specimens. In recent $H$. amphibius, these flock together to crèches (Verheyen, 1954) whereas the males live much farther apart from one another in territories with strict delimitations.

Much of the ferocious fighting is caused by territorial problems, and it is difficult to imagine an entirely changed behaviour pattern in which adult males share the same narrow space with each other and with females and juveniles. Future excavations could bring more information on this theme.

\section{d. Origin and preservation of the Hippopotamus creutzburgi type}

It is probable that Crete emerged as an island during some alpine phase of folding in the Oligocene of Early Miocene. Between Middle Eocene and Middle Miocene there is a large hiatus on Crete that is not yet filled. Anyhow, Eocene strata are always strongly folded and very altered, whereas the Neogene strata of Crete are at most tilted. Among the latter, there 


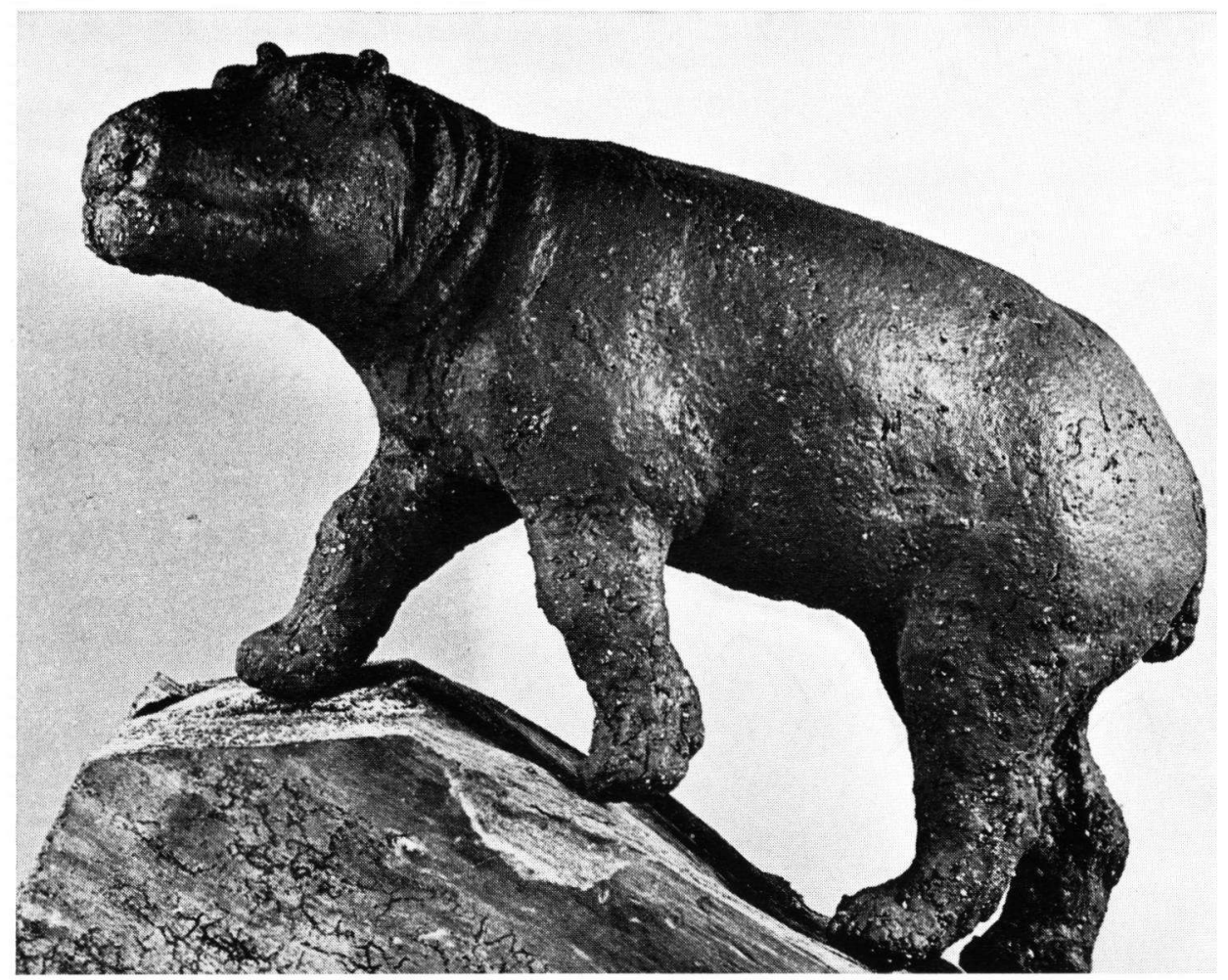

Fig. 8. Reconstruction of Hippopotamus creutzburgi by Mrs. A. A. Sondaar-Dobbelmann. 
are several fresh-water deposits. Those near Viano, those in the region of Kanli Kastelli, and those near Phaneromeni yielded molluscs and fresh-water ostracoda as well as plant fossils. At Chersonisos some fish fossils (scales, skeleton elements) were met with, and the same were encountered in the lignite deposits of Vrises (notably some Cyprinid gill-bones) that contain iguana-like teeth and turtle fossils, but no fossil mammalia. The only Neogene mammal hitherto found on Crete is some species of Sirenian, discovered by Boekschoten in the brackish deposits of Dhouli.

On many places of the island the Neogene coastlines are still visible; it seems that Crete presented itself as a series of mountainous islands, separated by shallow channels. The karst erosion started during the Neogene already, as Pliocene deposits W of Iraklion overlie karstified abrasion terraces of Cretaceous rudist limestone.

It is understandable that an aquatic mammal such as the Hippopotamus colonised the island. From the Greek mainland several finds of Pleistocene Hippopotamus amphibius were described (Psarianos, 1953; Thenius, 1955; Melentis, 1965, Milojcic et al., 1965) and the Greek mainland is the nearest (about $95 \mathrm{~km}$ ) to Crete. Colonisation from the Turkish mainland is not altogether impossible, but a number of factors make this less probable. The distance between Turkey and Crete (about $180 \mathrm{~km}$ ) is greater. No finds are known from the intercalated islands of Rhodos and Karpathos. The Cypriotic Hippopotamus minor possibly was derived from some Turkish hippo, but it differs so much in its dentition from other Mediterranean island forms that it is debatable whether this form arose from an amphibius ancestor (although this is contended by LEonardi, 1948).

There is a striking parallelism between Hippopotamus creutzburgi and $H$. melitensis. Both show a marked decrease in size, and both have certain morphological peculiarities that seem to be adaptations to island life. The conclusion seems unescapable that at some moment or other some Mediterranean islands were invaded by stray Hippopotamus amphibius that settled in the relatively scarce suitable environments available. As the animals have few natural enemies, they grew rapidly in number and probably some kind of hippo problem such as in East Africa (BERE, 1959) presented itself. Overgrazing led to soil erosion and destruction of otherwise suitable biotopes. Overpopulation led to spreading of hippos into less readily acceptable environments. All this exerted selective pressure, putting at an advantage those individuals that needed less food and could afford to be less particular about the quality of the food; that could climb rough mountainsides and tread on stony paths in order to reach far-off pastures; that were less dependent on shallow water for shelter; and could also do with caves instead.

Thus a specialized group of hippos came into being, probably within a short period of time, about the order of a millenium (compare also general remarks on the nanism problem, next paragraph). It is very probable that several hippo invasions took place, but that later Hippopotamus amphibius found suitable environments already occupied by $H$. creutzburgi that was better adapted to local circumstances. Thus, $H$. creutzburgi was preserved as a discrete form (Fig. 8), and invasion of amphibius-types of hippos did not interfere with the development of the specialisation tendencies.

An important question is, whether the Cretan hippo could arise from an ancestral stock that was already smaller than normal $H$. amphibius. The Greek fossil hippos are of amphibius stature, but some inland examples of a smaller Hippopotamus are known from Slovenia and Austria. These were described as H. pentlandi by Rakovec (1954) and Thenius, Hofer and Preisinger (1959).

The present authors think it highly unlikely that these hippos really belong to the Sicilian form. An alternative explanation could be presented by the fact that smaller races of several species of large mammals (buffaloes, African elephants etc.) occur in dense forests where they are at an advantage when circulating through the crowded vegetation. Detailed osteological comparison between the continental hippopotami that were named pentlandi and the island form could be rewarding. Such specimens of $\boldsymbol{H}$. pentlandi as we could study in the British Museum (Falconer collection, Grotta di Maccagnone, Sicily) fall within the size range of $H$. amphibius.

\section{e. Remarks on the problem of nanism}

The occurrence of forms of aberrant dimensions on islands was noted long ago. One of the best-known cases is that of the Porto Santo dwarf rabbit that was dealt with by Darwin. According to Nachtsheim (1941) this diminutive race of Oryctolagus cuniculus developed in only four hundred years of isolation on a small island of the Canaries archipelago. The phenomenon occurs also in deer and in elephants, whereas gigantism is noted in other cases (e.g. Leithia on Malta). The dwarf hippopotamus is not the only form of small stature, that occurs on Crete. Recently Kuss 
(1965) published a very interesting and stimulating paper on his finds in a cave near Sisses in Middle Crete. He described a supposed relative of the African elephant under the name Loxodonta creutzburgi kuss, that is about as large as the recent Loxodonta. Furthermore, Dr. Kuss extended our knowledge of Megaceros cretensis (Simonelli), which is a diminutive representative of the genus. Earlier, Miss BATE (1907) described a dwarf elephant under the new name Elephas creticus Bate.

The description of these island forms poses the same type of problems we meet with when investigating the hippopotami. Therefore, it seems desirable to digress on the dwarf Megaceros that arose on Crete under the same circumstances that must have shaped H. creutzburgi. The features of Megaceros cretensis are well known now through the lucid and painstaking description of Dr. Kuss. The present authors cannot agree, however, with all of his conclusions. Just as earlier authors (Azzarol, 1961 etc.) did, Dr. Kuss regards many peculiarities of $M$. cretensis as degenerative. The grooves in the tusks of Loxodonta creutzburgi are ingeniously explained, but in this case the trunk of the animal is described as weakened. Degeneration was already suggested by LEONARDI (1948) for the phenomenon of the dwarf hippopotami.

The word degeneration, however, seems to us unapplicable to organisms that proved so successfully adapted to their environment. In our opinion it is rather specialisation that accounts for the morphologic changes which the insular forms underwent. They were, as we have seen and as we will try to demonstrate further, very well adapted to the peculiarities of their biotope. One of these peculiarities was the absence of predators. Fossil carnivores have not yet been found on Crete, and it is improbable that they will ever be met with, as they are also conspicuously absent on the other Mediterranean islands. Apparently, the expanse of water to be crossed was an insurmountable obstacle. It is possible also that the coastal zone was too poor in prey to hold the carnivores. Several defence systems that the Cretan deer inherited from their continental ancestry lost much of their importance, as only intraspecific agression could occur.

Dr. Kuss considers the following features as companion symptoms to nanism in this Megaceros:

1. totally worn-down teeth;

2. fusion of tarsus bones;

3. hyperostosis of the skull and bones;

4. deformation of the hearing bones.
In our opinion, these deflections are not related to nanism but are those of gerontic individuals that were not removed through predators.

Another feature is the simplification of the antlers, noted by Dr. Kuss. This point is not to be overestimated as it is known that antlers can undergo considerable morphological changes due to changes in nutrition within one generation (a.o. Walvius, 1961). The hypsodonty of the teeth, noted by Dr. Kuss, points to hard food and we agree with him in this respect. It has, however, no direct bearing on the nanism phenomenon; it presents some indication of environmental influences that could also alter the shape of the antlers.

Dr. Kuss describes other features linked according to him with nanism. These are: short muzzles and short extremities, and he considers these as main features of the process of nanism. In our opinion, these characteristics point to an "antilopised" pattern of life that the Megaceros deer were compelled to lead on the barren Island of Crete. They are not directly related to the phenomenon of nanism, and they are comparable with the modifications found in limb bones of Hippopotamus creutzburgi.

When so many characteristics are readily connected with adaption to island life, it is considered as improbable by the present authors that diminution of size is a degenerative process caused by "inner causes" such as physiological unbalancing due to climatic influences. This supposition is adhered to by Dr. Kuss. It must be remarked, however, that the ecological range of many large mammals is rather large without large phenotypic variation occurring

Contrary to the opinion of Dr. Kuss, we think that food shortage can be an important point on islands for mammals that depend on the vegetation for their nutrition, and that are not controlled by predation. In a period of famine, small individuals needing less food are certainly at an advantage. The small size is also advantageous when taking shelter in caves, as Dr. Kuss thinks the Megaceros did. Contrariwise, physiological unbalance, supposed by Dr. Kuss, seems hard to reconcile with the observation of the same author, that many deer grew very old on Crete. If degeneration were indeed the cause, it would be difficult to explain why the animals thrived as they did. In our opinion, the extinction of the endemic fauna of Crete was caused by climatic changes that occurred so quickly that the animals could not cope with the sudden alteration of their biotope. This explanation was already invoked by Miss BATE (1906) for the Cypriotic hippopotamus. 


\section{RESUME}

On décrit Hippopotamus creutzburgi, nouvelle espèce naine d'hippopotame de l'Ile de Crète. Elle se distingue de l'hippopotame actuel par ses dimensions plus réduites et par la structure des pattes qui sont plus adaptées à la marche qu'à la nage. Cet hippopotame vivait probablement pendant la pleistocène moyen.

\section{ZUSAMMENFASSUNG}

Hippopotamus creutzburgi, eine neue Zwergform des Flusspferdes, wird aus vermutlich mittelpleistozänen
Ablagerungen der Insel Kreta beschrieben. Die neue Art ist vom rezenten $H$. amphibius hauptsächlich durch die geringere Grösse und die Ausbildung der Extremitäten, die mehr zum laufen geeignet sind, zu unterscheiden.

\section{SUMMARY}

A new species of dwarf hippopotamus, Hippopotamus creutzburgi, is described from probably Middle Pleistocene lacustrine deposits of the Island of Crete. The main points of difference from the common hippo are its reduced size and the specialization of its legs, which are better adapted to walking.

\section{REFERENCES}

AcCoRDI, B., 1955: Hippopotamus pentlandi von Meyer del pleistocene della Sicilia. Paleontogr. Italica 50, Paleontologia ed ecologia del quaternario III, Memoria, N. 1, 1-52.

Azzaroli, A., 1961: Il nanismo nei cervi insulari. Paleontogr. Italica 56, 1-32.

BATE, D. M. A., 1905: Four and a half month in Crete in search of Pleistocene mammalian remains. Geol. Mag., Dec. V, 2, 193-202.

- 1906: The pygmy Hippopotamus of Cyprus. Geol. Mag., Dec. V, 3, 241-245.

- 1907: On elephant remains from Crete, with description of Elephas creticus. Proc. Zool. Soc. London, 238250.

BERE, R. M., 1959: The Hippopotamus problem and experiment. Oryx 5, 116-124.

BLAinville, H. M. D. DE, 1847: Ostéographie, fasc. 22: Hippopotamus et Sus. Paris.

BoEksChoten, G. J., 1963: Some geological observations on the coast of Crete. Geol. en Mijnbouw 42, 241-247.

BüTtIKoFER, J., and C. F. SALA, 1883: Mededelingen over Liberia no. 12.

Creutzburg, N., 1958: Probleme des Gebirgsbaues und der Morphogenese auf der Insel Kreta. Freiberger Univ. Reden (N.F.) 26.

- 1961: Uber junge Verschüttungserscheinungen auf der Insel Kreta und ihre Beziehungen zum Klima des Pleistozäns. Praktika Akad. Athinon 35, 293-306.

Dekeyser, P. L., 1954: L'Hippopotame nain. Notes Africaines. Bull. Inst. Fr. Afr. Noire 64, 91-92.

Depéret, C., 1921: La phylogénie des Hippopotames. C.R.S.Soc. Géol. France, Sér. 4, 21, 163-165.

Falconer, H., 1860: On the ossiferous Grotta di Maccagnone, near Palermo. Quart. Journ. Geol. Soc. London 16, 99-106.

FERRIANS, O. J., 1963: Glaciolacustrine diamicton deposits in the Copper river basin, Alaska. U.S. Geol. Surv., Prof. Paper 475-C, 121-125.

Flint, R. F., J. E. Sanders, and J. Rodgers, 1960a: Symmictite. Bull. Geol. Soc. Amer. 71, 507-510.
- 1960b: Diamictite, a substitute term for symmictite. Bull. Geol. Soc. Amer. 71, 1809.

Gregory, W. K., 1951: Evolution emerging. Vol. I and II. New York.

GrZimEK, B., 1956: Einige Beobachtungen an Wildtiere in Zentral-Afrika. Z. für Tierpsychologie 13, 143-150.

HEDIGER, H., 1953: Ein symbioseartiges Verhältnis zwischen Flusspferd und Fisch, Säugetierk. Mitt. 1, 75-76.

HooIJeR, D. A., 1946: Notes on some Pontian mammals from Sicily, figured by Seguenza. Arch. Néerl. Zool. 7, 301-333.

- 1950: The fossil Hippopotamidae of Asia, with notes on the recent species. Zool. Verh. Rijksmus. Nat. Hist. Leiden 8.

KUss, S. E., 1957: Altpleistozäne Reste des Hippopotamus antiquus Desmarest vom Oberrhein. Jhb. Geol. Landesamt Baden-Württ. 2, 299-331.

- 1965: Eine pleistozäne Säugetierfauna der Insel Kreta. Ber. Naturf. Ges. Freiburg 55, 271-348.

LeONARDI, P., 1948: L'Ippopotamo del Valdarno. Paleontogr. Italica $43,17-44$.

- 1954: Les mammifères nains du Pleistocène méditerranéen. Ann. Paléont. 40, 189-201.

LYDEKKER, R., 1885: Catalogue of the fossil mammalia in the British Museum, part II.

Melentis, J. K., 1965: Uber Hippopotamus antiquus Desmarest aus dem Mittelpleistozän des Beckens von Megalopolis im Peloponnes (Griechenland). Ann. Géol. Pays Hellén. 16, 403-435.

Milojcic, V., J. Boessneck, D. Jung and H. Schneider, 1965: Paläolithikum um Larissa in Thessalien. Bonn.

NachtsheiM, F., 1941: Das Porto-Santo Kaninchen. Umschau, Frankfurt, 4 p.

OWEN, R., 1845: Catalogue of the fossil organic remains of mammalia and aves contained in the Museum of the Royal College of Surgeons of England. London, 391 p.

Psarianos, P., 1953: Uber das Vorkommen von Hippopotamus auf Kephallinia (Griechenland). Praktika Akad. Athinon 28, 408-412. 
- 1961: Karstika fainomena tis Ellados. I. Dolini Irakliou Kritis. Ann. Géol. Pays Hellén. 9, 186-190.

Rakovec, I., 1954: Hippopotamus from the Postojna Basin. Acad. Scient. Art. Slovenica, Cl. IV, Hist. Nat., 299-317.

ReYNOLDS, S. H., 1922: A monograph on the British Pleistocene mammals, III, 1. Hippopotamus. Paleont. Soc. London, 1920, 1-38.

SPRATr, T. A. B., 1865: Travels and researches in Crete. London.

STrömer, E., 1914: Mitteilungen über Wirbeltierreste aus dem Mittelpliozän des Natrontales (Ägypten), 3, Artiodactyla: A, Bunodontia: Flusspferd. Zeitschr. Deutsch. Geol. Ges. 66, 1-33.

ThEnIUs, E., 1955: Studien über fossile Vertebraten Griechenlands. V. Hippopotamus aus dem Astien von
Elis (Peloponnes). Ann. Géol. Pays Hellén. 6, 206-212. TheniUs, E. and H. Hofer, 1963: Stammesgeschichte der Säugetiere. Berlin.

Thenius, E., H. Hofer and A. Preisinger, 1959: Hippopotamus pentlandi und die Alterseinstufung der Arsenalterrasse von Wien. Verh. Geol. Bundesanst. Wien, 129131.

Verheyen, R., 1954: Monographie éthologique de l'hippopotame. Inst. Parc. Nat. Congo Belge, Explor. Parc Nat. Albert. Bruxelles.

VIRET, J., 1961: Artiodactyla. In: J. Piveteau, Traité de Paléontologie 6, 953.

Walvius, M. R., 1961: A discussion of the size of recent red deer (Cervus elaphus L) compared with prehistoric specimens. Beaufortia 9, 75-82. 
PLATES 


\section{PLATE I}

Hippopotamus creutzburgi nov. sp.

1. Maxilla with $\mathrm{P}^{4}-\mathrm{M}^{3}$ B.M.N.H. cat. no. M 10286

2. Right $\mathrm{M}^{2} \mathrm{M}^{3} \quad$ B.M.N.H. cat. no. M 10305 Kharoumes cave (Crete).

\section{PLATE II}

Hippopotamus creutzburgi nov. sp.

$\begin{array}{ll}\text { 1. Mandibula } & \text { B.M.N.H. cat. no. M } 10287\end{array}$ Katharo (Crete) paratype

2. Left M2Ms B.M.N.H. cat. no. M 10289 Katharo (Crete)

Hippopotamus melitensis Forsyth Major

3. Left M2 B.M.N.H. cat. no. M 12499 Ghar Dhalam cave (Malta)

\section{PLATE III}

Hippopotamus minor Desmarest

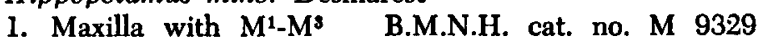
Dikomo-Mandra (Cyprus)

2. Right maxillary part with $\mathrm{P}^{2} \mathrm{P}^{3} \mathrm{DP}^{4} \mathrm{M}^{1} \mathrm{M}^{2}$ Agios Saronda (Cyprus)

B.M.N.H. cat. no. M 9344

Hippopotamus creutzburgi nov. sp.

3. Left maxillary part with $\mathrm{DP}^{4} \mathrm{M}^{1} \mathrm{M}^{2}$ Katharo (Crete)

B.M.N.H. cat. no. M 10288

4. Left mandible fragment with $\mathrm{DP}_{3} \mathrm{DP}_{4} \mathrm{M}_{1}$ Katharo (Crete)

B.M.N.H. cat. no. M 10296

\section{PLATE IV}

Hippopotamus minor Desmarest

$\begin{array}{ll}\text { 1. Right Ms } & \text { B.M.N.H. cat. no. M } 9300\end{array}$ Cyprus

Hippopotamus melitensis Forsyth Major

2. Left Ms B.M.N.H. cat. no. M 12498 Ghar Dhalam cave (Malta)

Hippopotamus pentlandi von Meyer

3. Right Ms B.M.N.H. cat. no. M 4186 Maccagnone (Sicily)

Hippopotamus creutzburgi nov. sp.

4. Left Ms B.M.N.H. cat. no. M 10295 Katharo (Crete)

5. Upper right canine B.M.N.H. cat. no. M 10290 Katharo (Crete)

Hippopotamus melitensis Forsyth Major

6. Upper left canine B.M.N.H. cat. no. R 49325-6 Malletta cave (Malta)

Hippopotamus cf. amphibius Linnaeus

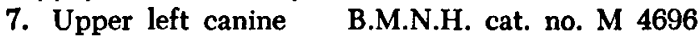
Ghar Dhalam cave (Malta)

\section{PLATE V}

Hippopotamus creutzburgi nov. sp.

1. Left distal tibia fragment B.M.N.H. cat. no. $M$ 10299

Katharo (Crete)

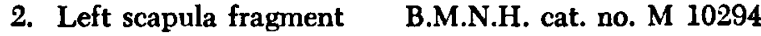
Katharo (Crete) paratype

3. Fragment left calcaneum 10300

Katharo (Crete)

4. Right navicular B.M.N.H. cat. no. M 10301

a. Proximal view

b. Distal view

Katharo (Crete) paratype

Hippopotamus amphibius Linnaeus

5. Left navicular G.I.U.
a. Proximal view

b. Distal view

\section{PLATE VI}

Hippopotamus amphibius Linnaeus

1. Left astragalus (reversed) G.I.U.
a. Anterior view
b. Posterior view
c. Distal view
d. Medial view

Hippopotamus creutzburgi nov. sp.

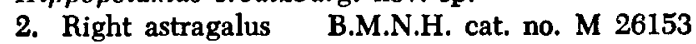
Katharo (Crete) paratype
a. Anterior view
b. Posterior view
c. Distal view
d. Medial view

\section{PLATE VII}

Hippopotamus creutzburgi nov. sp.

1. Left metacarpal III - metacarpal IV B.M.N.H. M 10302 (different individuals)

Katharo (Crete)

3. Left metatarsal III B.M.N.H. cat. no. M 10302 Katharo (Crete)

a. Anterior view

b. Posterior view

5, 6. Phalange I B.M.N.H. cat. no. M 10302

Katharo (Crete)

a. Anterior view

b. Posterior view

Hippopotamus melitensis Forsyth Major

2. Right metatarsal III B.M.N.H. cat. no. M 12310 Ghar Dhalam cave (Malta)

a. Anterior view

b. Posterior view

4. Phalanx I B.M.N.H. cat. no. M 12469

Ghar Dhalam cave (Malta)

a. Anterior view

b. Posterior view 

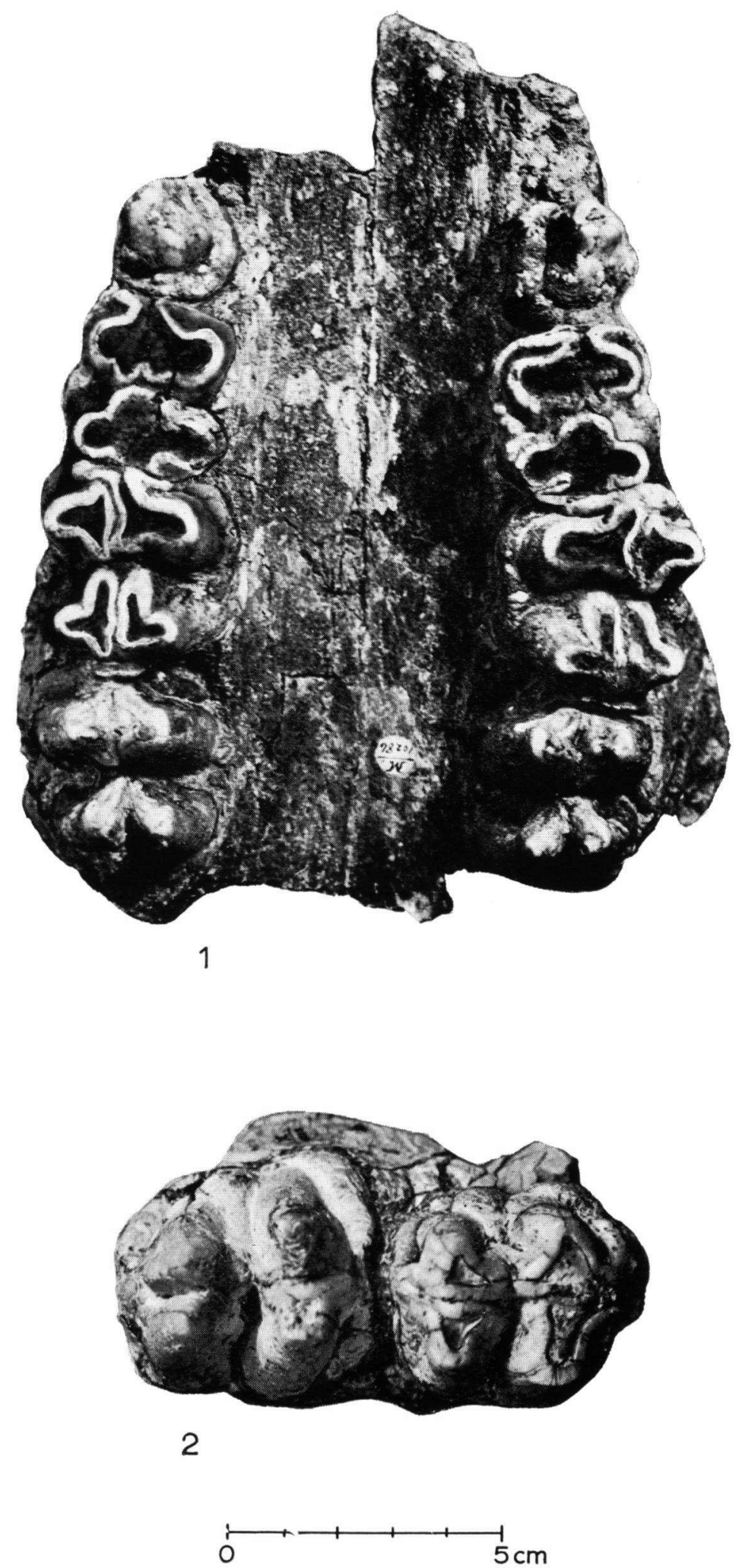

PLATE I 

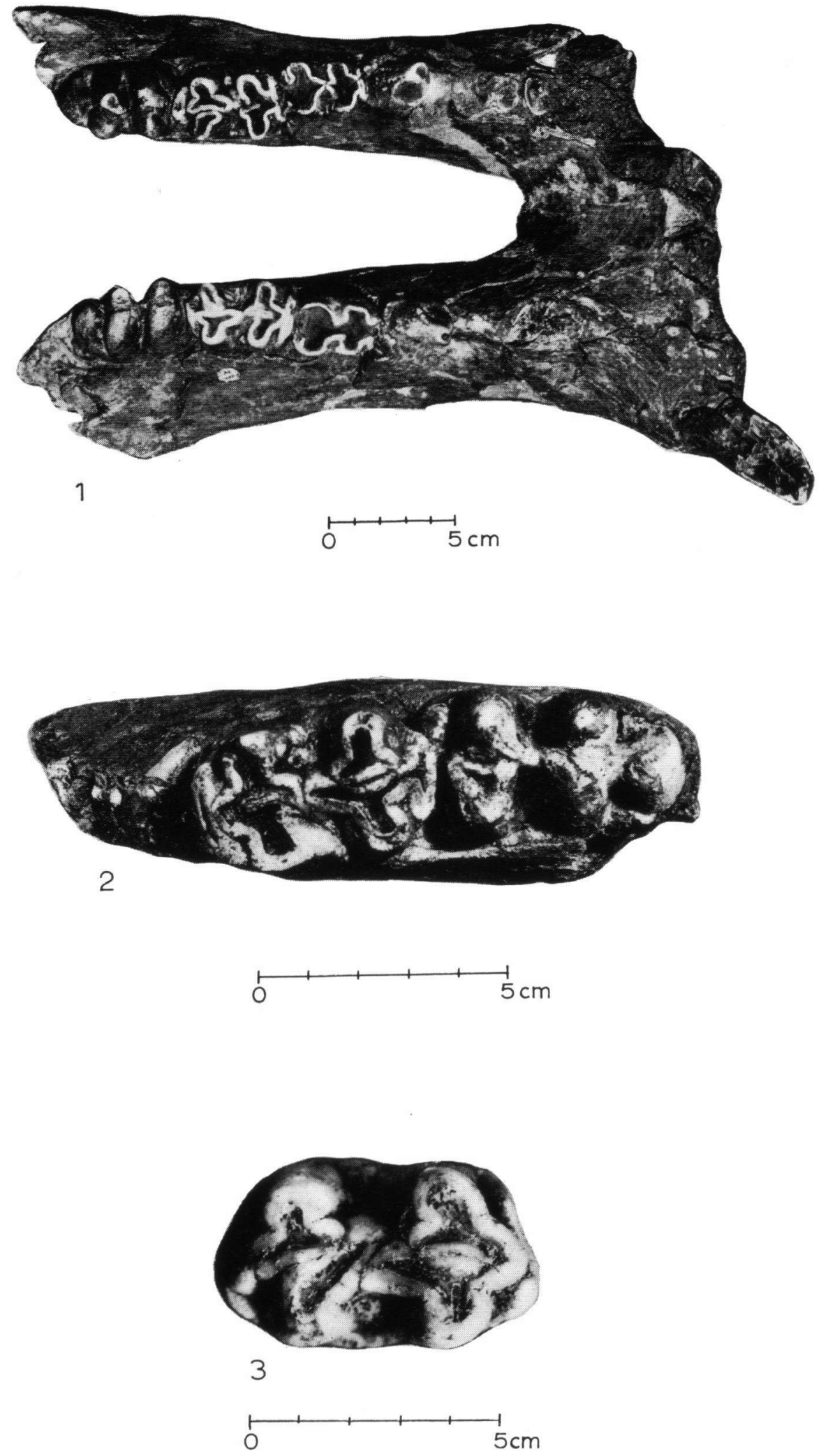


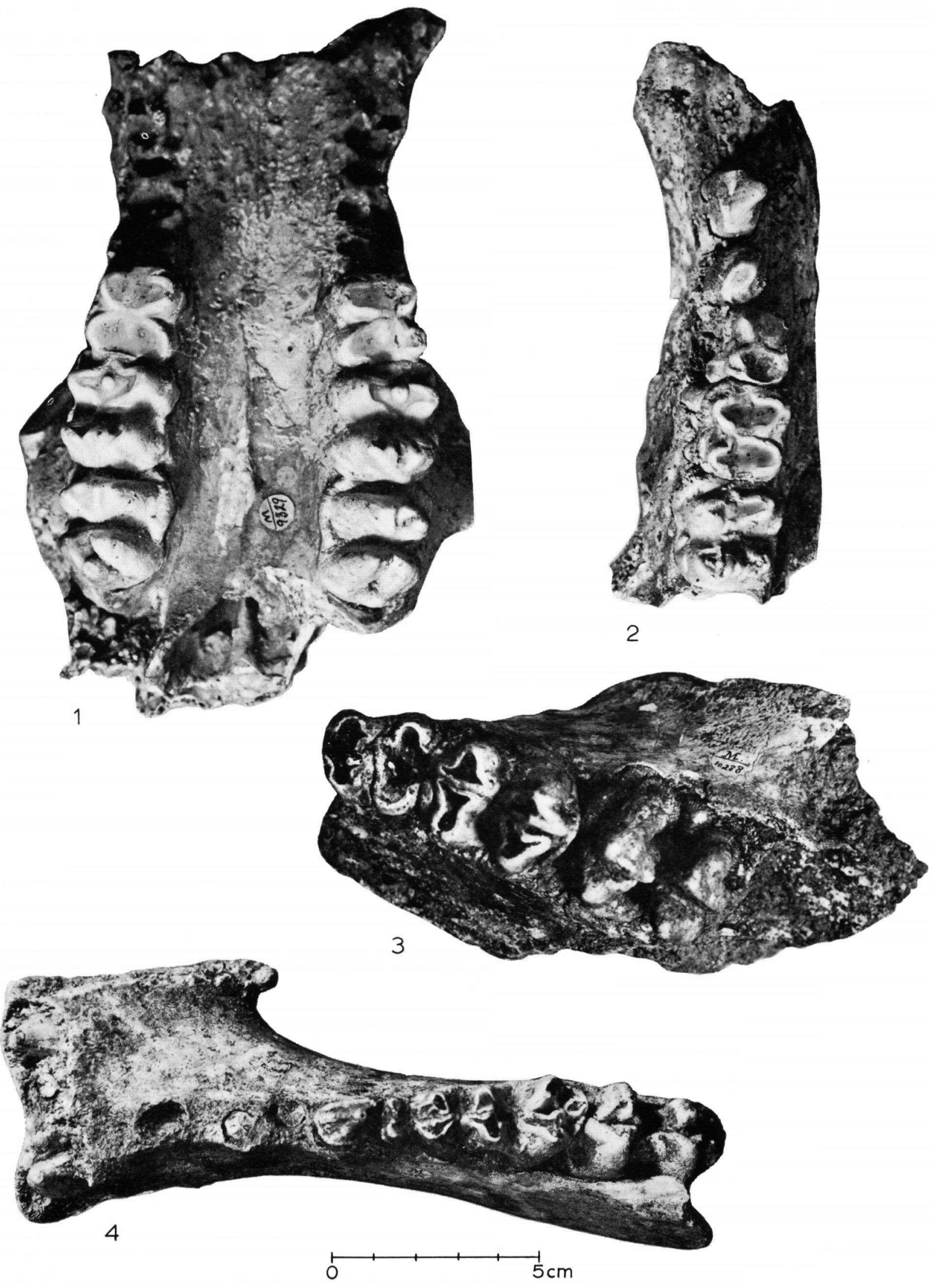

PLATE III 

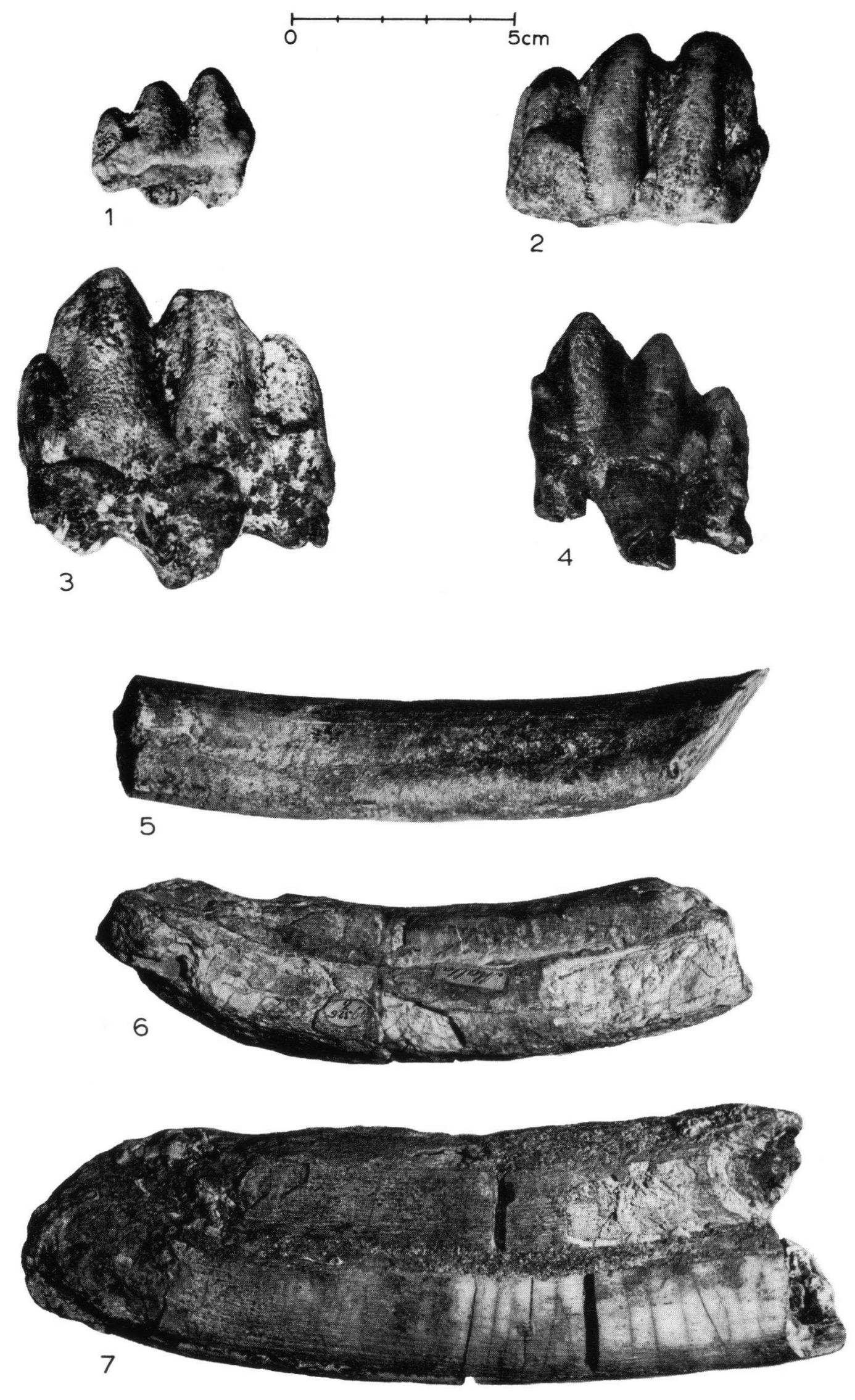

PLATE IV 

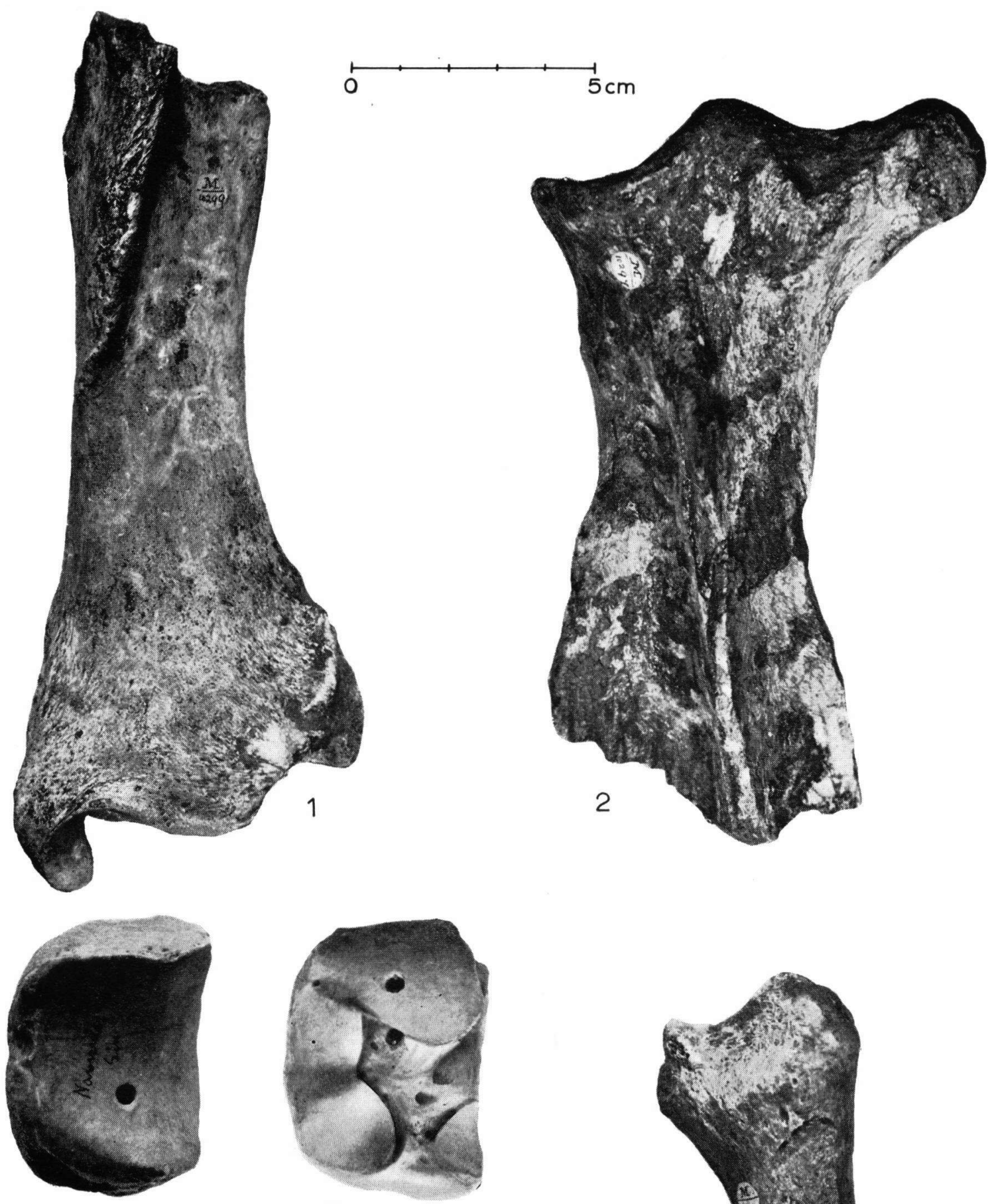

$4 a$

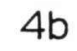

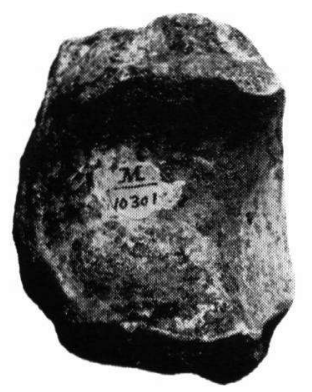

$5 a$

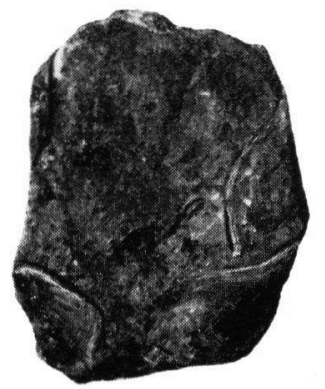

$5 b$

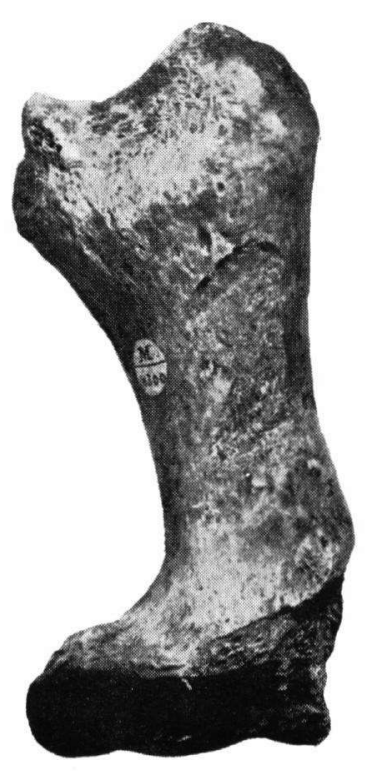

3 

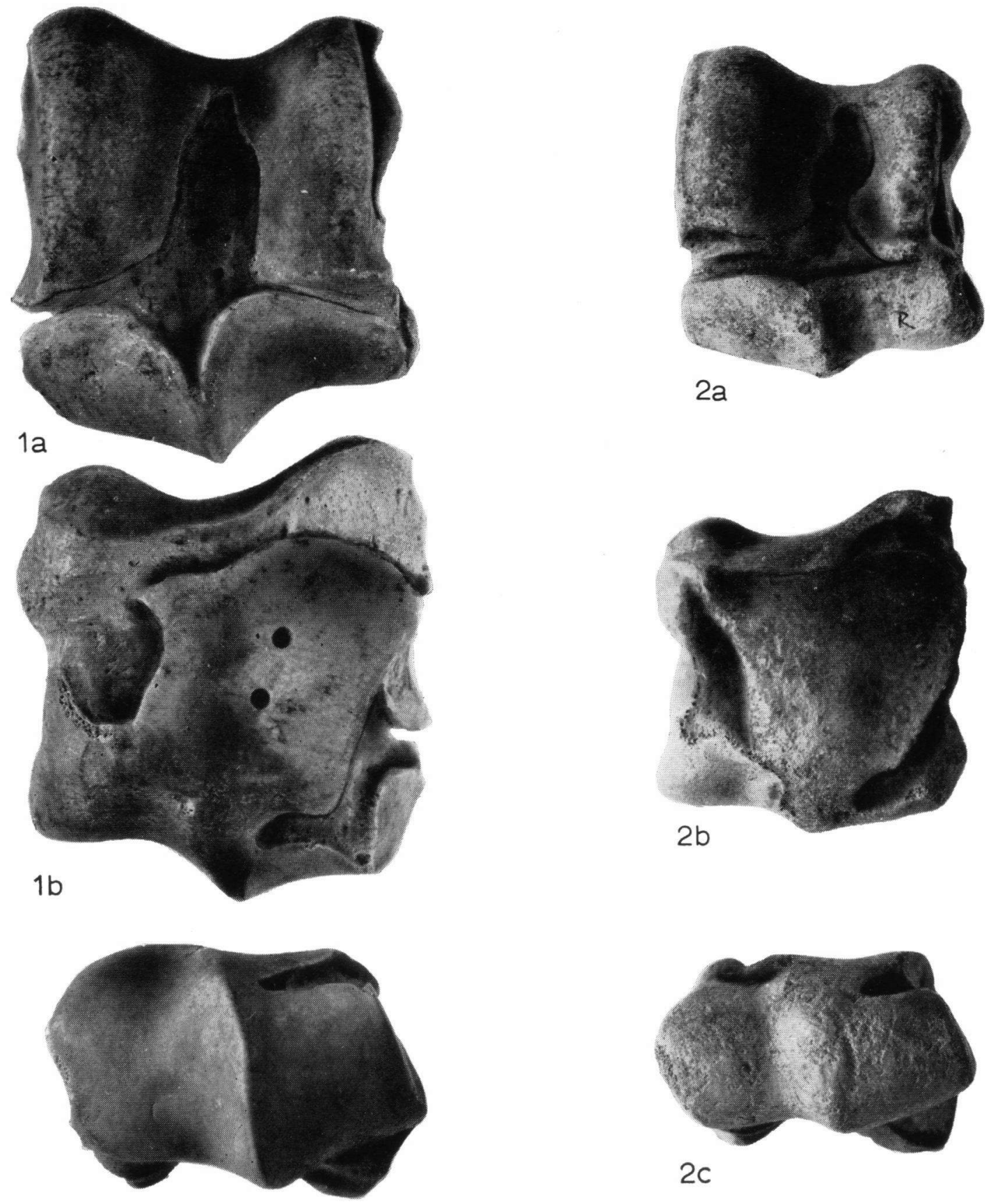

$1 c$

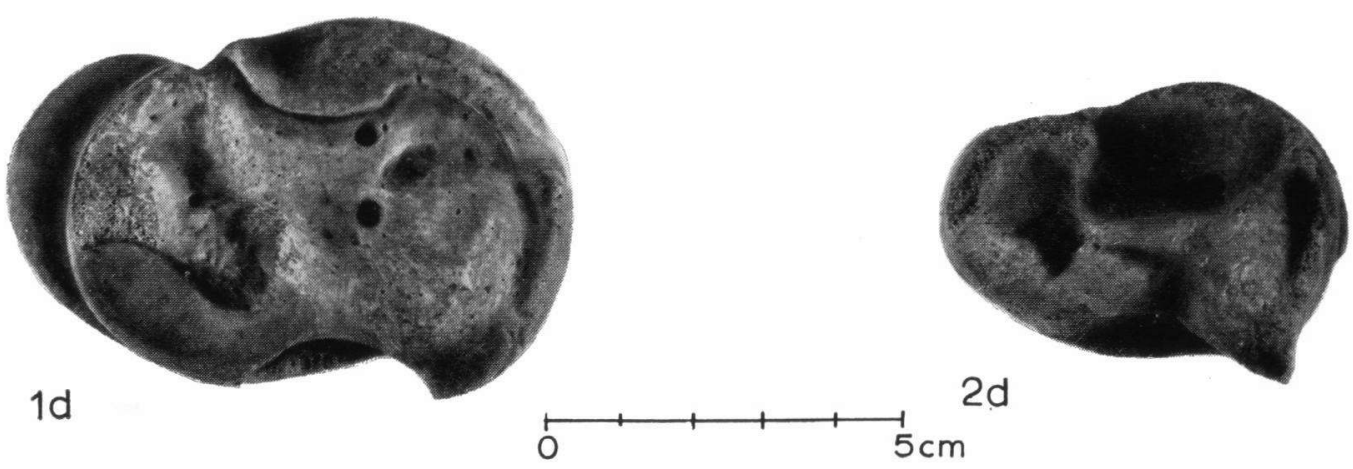

PLATE VI 


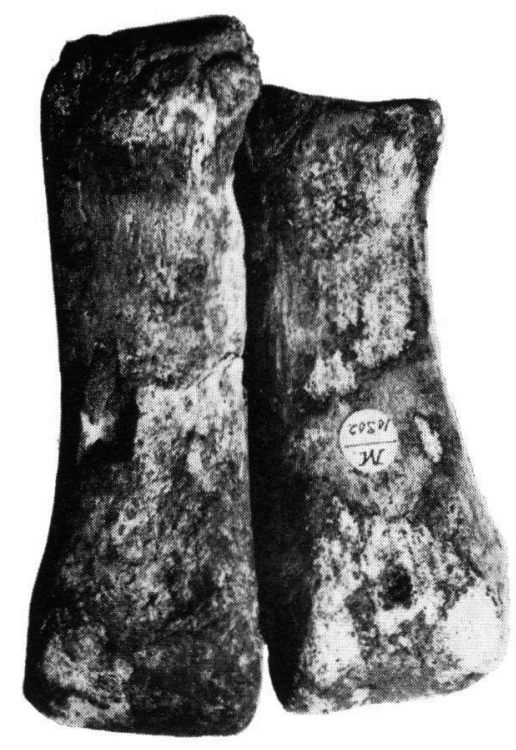

1

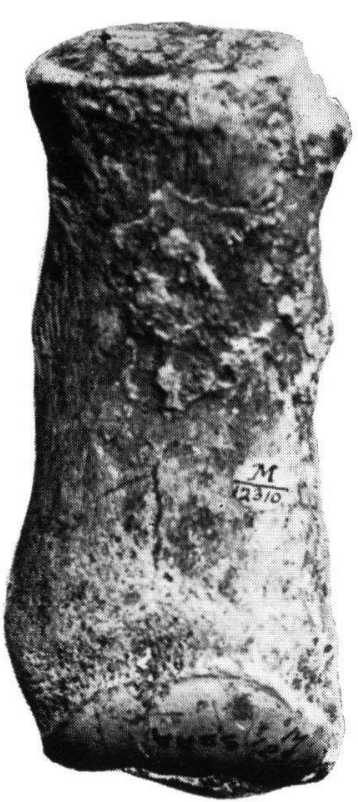

$2 a$

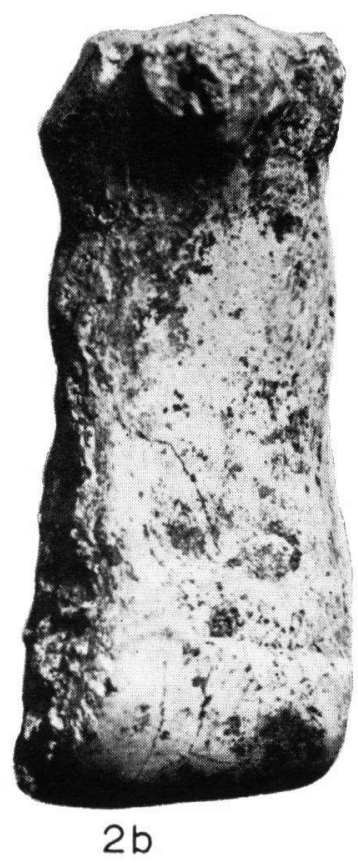

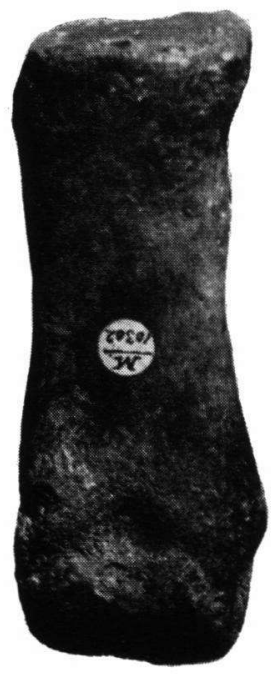

$3 a$

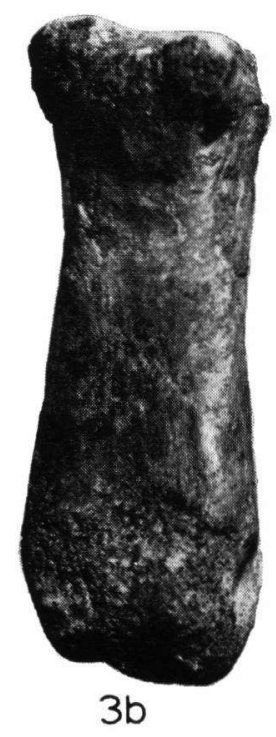

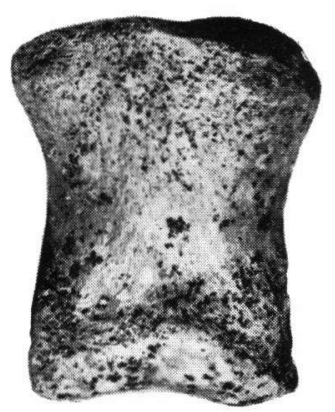

$4 a$

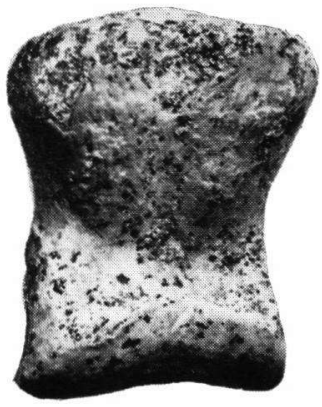

$4 b$

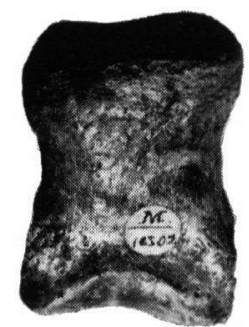

$5 a$

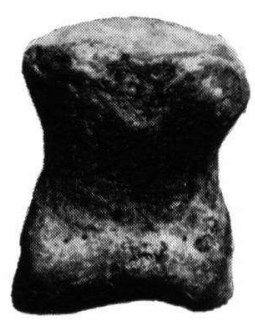

$5 b$

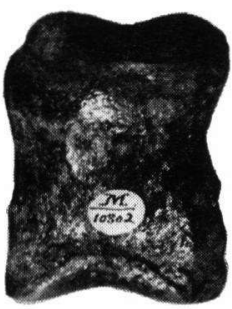

$6 a$

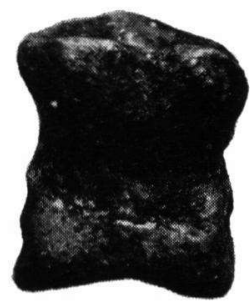

$6 b$ 